\title{
Structure-Based Design of Potent Selective Nanomolar Type-II Inhibitors of Glycogen Synthase Kinase-3 $\beta$
}

Matthew P. Davies, Rocio Benitez, Concepción Perez, Sven Jakupovic, Philip Welsby, Klaudia Rzepecka, Jane Alder, Colin Davidson, Ana Martinez,* and Joseph M. Hayes*

Cite This: J. Med. Chem. 2021, 64, 1497-1509

Read Online

ABSTRACT: For the first time, the in silico design, screening, and in vitro validation of potent GSK-3 $\beta$ type-II inhibitors are presented. In the absence of crystallographic evidence for a DFG-out GSK-3 $\beta$ activation loop conformation, computational models were designed using an adapted DOLPHIN approach and a method consisting of Prime loop refinement, induced-fit docking, and molecular dynamics. Virtual screening of the Biogenics subset from the ZINC database led to an initial selection of 20 Phase I compounds revealing two low micromolar inhibitors in an isolated enzyme assay. Twenty more analogues (Phase II compounds)

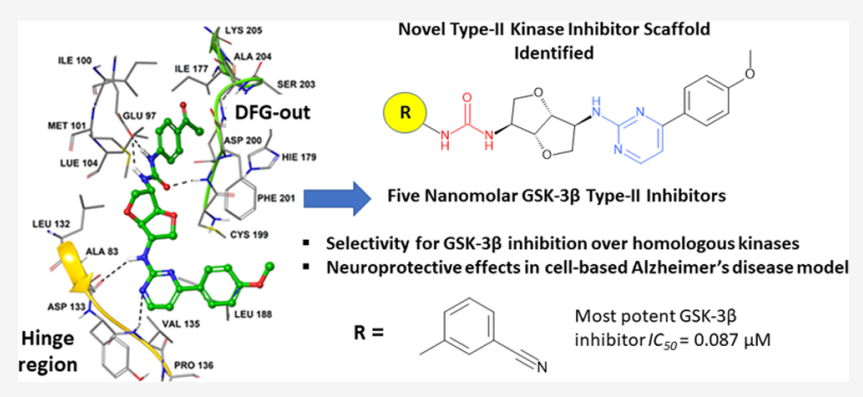
related to the hit [pyrimidin-2-yl] amino-furo[3,2-b]furyl-urea scaffold were selected for structure-activity relationship analysis. The Phase II studies led to five highly potent nanomolar inhibitors, with compound $23\left(\mathrm{IC}_{50}=0.087 \mu \mathrm{M}\right)>100$ times more potent than the best Phase I inhibitor, and selectivity for GSK-3 $\beta$ inhibition compared to homologous kinases was observed. Ex vivo experiments (SH-SY5Y cell lines) for tau hyperphosphorylation revealed promising neuroprotective effects at low micromolar concentrations. The type-II inhibitor design has been unraveled as a potential route toward more clinically effective GSK-3 $\beta$ inhibitors.

\section{INTRODUCTION}

Alzheimer's disease $(\mathrm{AD})$ is a neurodegenerative disease and the most common form of dementia. Approximately 50 million people worldwide suffer from the condition. ${ }^{1}$ However, current treatments do little more than partially alleviate some symptoms or slow down the progression of the disease. According to the "GSK-3 hypothesis of Alzheimer's disease", the increased activity and/or overexpression of the Ser/Thr kinase, glycogen synthase kinase-3 $\beta$ (GSK-3 $\beta$ ), is linked with both tau hyperphosphorylation and alterations in amyloid- $\beta$ processing, primers for formation of neurofibrillary tangles and senile plaques in $\mathrm{AD}$, respectively. ${ }^{2,3}$ Furthermore, GSK- $3 \beta$ is highly expressed in the brain, is localized primarily in neurons, ${ }^{4}$ and its overactivity has been associated with neuronal loss. ${ }^{5}$ GSK-3 $\beta$ inhibition, therefore, is viewed as an important target toward much-needed new treatments, and recent findings that GSK- $3 \beta$ inhibitors ameliorate cognitive impairments caused by $\mathrm{AD}$ have led to a couple of candidates entering clinical trials. ${ }^{6-8}$ Importantly, GSK-3 $\beta$ is also attracting considerable interest as a therapeutic target for a number of other conditions such as bipolar disorder, Parkinson's disease, epilepsy, cancer, and type 2 diabetes. $^{9-12}$

GSK-3 $\beta$ is phylogenetically related to other kinases sharing the greatest homology with the cyclin-dependent kinases (CDKs), protein kinase C (PKC), and mitogen-activated protein kinases (MAPKs). ${ }^{13}$ Because of this homology, the design of potent and kinase selective type-I (adenosine 5'triphosphate, ATP-binding site) inhibitors is challenging from a drug design perspective, with the highly conserved kinase Asp-Phe-Gly (DFG) motif of the activation loop orientated toward the binding site (DFG-in, active conformation). The design of ATP-binding site inhibitors of GSK-3 $\beta$ has been extensively explored, ${ }^{14,15}$ and researchers are now turning to other types of inhibition so as to achieve inhibitors with better selectivity and efficacy. Some allosteric and substrate binding site inhibitors have been reported and reviewed. ${ }^{14,15}$

Design of inhibitors targeting the DFG-out inactive conformation (type-II inhibitors) has never been actively pursued for constitutively active GSK-3 $\beta$. However, the structural heterogeneity of the hydrophobic allosteric site immediately adjacent to the ATP-binding site, accessible in the "DFG-out" conformation, means that type-II inhibitors have potential for greater selectivity. ${ }^{16-18}$ FDA-approved clinical drugs such as imatinib (STI571) and sorafenib (BAY43-9006), which target other kinases, are type-II/DFG-

Received: September 8, 2020

Published: January 27, 2021 
Sorafenib<smiles>CNC(=O)c1cc(Oc2ccc(NC(=O)Nc3ccc(Cl)c(C(F)(F)F)c3)cc2)ccn1</smiles><smiles></smiles>

$0.86 \mu \mathrm{M}(0.057 \mu \mathrm{M})$<smiles>CC(C)(C)[14CH3]</smiles>

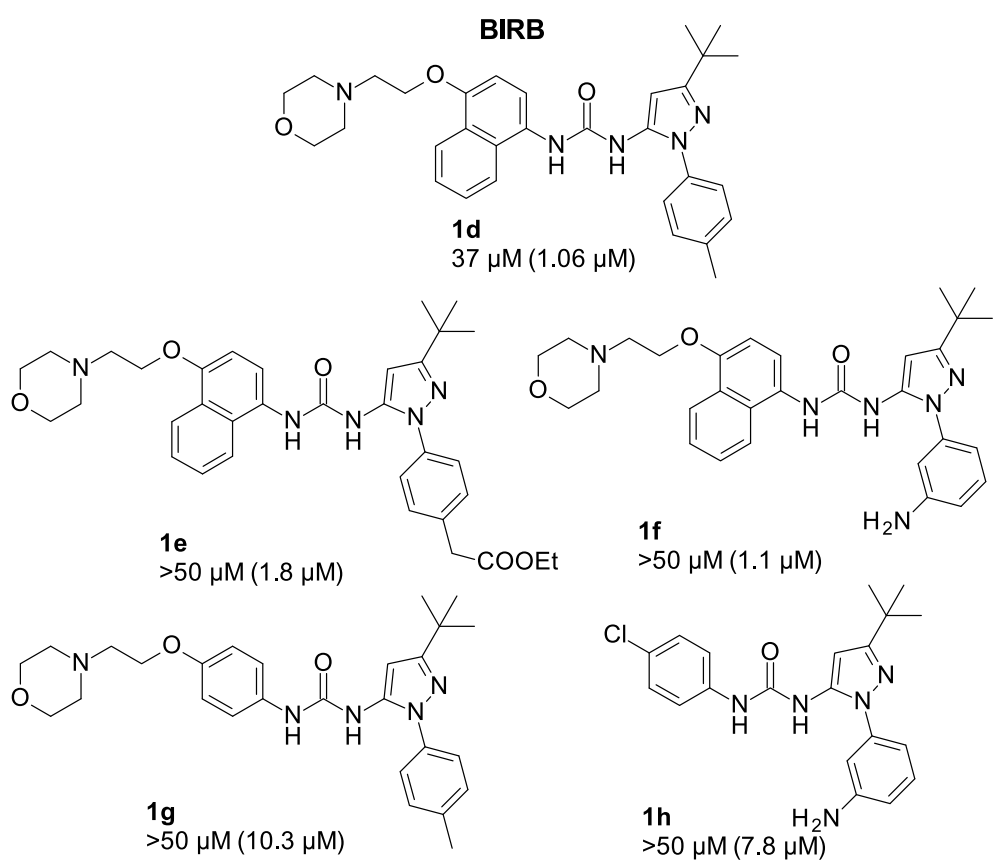

BIRB

$>50 \mu \mathrm{M}(7.8 \mu \mathrm{M})$

Figure 1. Type-II inhibitor set of compounds consisting of sorafenib $(\mathbf{1 a}-\mathbf{c})$ and BIRB-796 $(\mathbf{1 d}-\mathbf{h})$ analogues previously tested against GSK-3 $\beta$. $\mathrm{IC}_{50}$ inhibition data against both human and U. maydis (in parentheses) GSK-3 $\beta$ are given. ${ }^{23}$

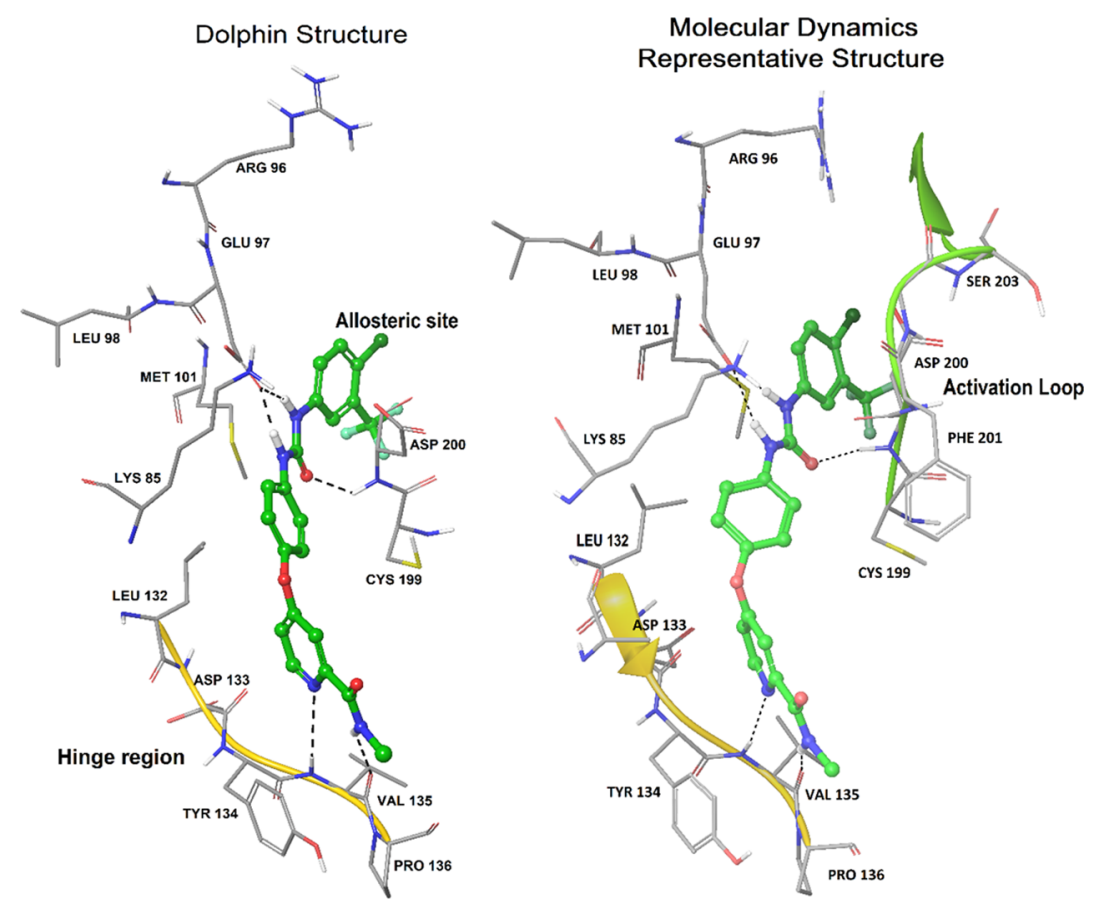

Figure 2. Predicted binding of sorafenib (1a) to GSK-3 $\beta$ using the DOLPHIN model (left) compared to the DFG-out model from the Prime/ molecular dynamics protocol (right). In both models, all of the classical type-II protein-ligand interactions are present and the now accessible allosteric site occupied. Protein-ligand hydrogen bonds are displayed as black dashed lines. PDB code $2 \mathrm{OW} 3$ was used as the initial starting model for calculations.

out inhibitors. Kinase structural features necessary for DFGout/type-II inhibition remain unclear, but the small L132 gatekeeper residue and the $x=\mathrm{C} 199$ residue of the $\mathrm{xDFG}$ motif in GSK- $3 \beta$ are consistent with the viability of this mechanism. $^{17-19}$ Studies have shown that C199 is a key residue in modulating GSK-3 $\beta$ activity, ${ }^{20,21}$ and covalent inhibition of GSK-3 $\beta$ has just been reported exploiting the C199 covalent interaction. ${ }^{22}$ Recently, evidence of the Ustilago maydis fungal form of GSK- $3 \beta$ undergoing type-II inhibition was reported. ${ }^{23}$ Some of the compounds studied revealed less potent inhibition of the human isoform (Figure 1) but nevertheless indicating that type-II inhibition is possible.

In this study, we present in silico screening using Glide docking $^{24}$ of natural-product-based compounds against two different predicted DFG-out models of GSK-3 $\beta$. The first structural model was generated used a DOLPHIN (Deletion 
Of Loop PHe-gly-IN)-type approach, ${ }^{25}$ which has previously reported successful applications. ${ }^{26}$ The second DFG-out model was created using a combination of Prime loop prediction, ${ }^{27,28}$ induced-fit docking (IFD), and then molecular dynamics $(\mathrm{MD})$ for a final structural refinement. The two models were both used to screen a database of compounds taken from the Biogenics subset of the ZINC15 database. ${ }^{29}$ An initial selection of 20 predicted type-II inhibitors (Phase I compounds) from the in silico screening identified [pyrimidin2-yl]amino-furo[3,2-b] furyl-ureas hit compounds following in vitro GSK-3 $\beta$ binding assay experiments. This led to a focused structure-activity relationship (SAR) analysis on an additional 20 analogues considering the hit scaffold (Phase II compounds). The best inhibitors (including five nanomolar potency compounds) were then tested ex vivo for their neuroprotective effects at the cellular level, with promising neuroprotective effects observed at low micromolar concentrations. Selected inhibitors demonstrated favorable kinase selectivity against closely related homologous kinases.

\section{RESULTS AND DISCUSSION}

2.1. Preliminary Computational Results. 2.1.1. DOLPHIN Model Validation. The first DFG-out model of GSK- $3 \beta$ was generated using an adapted DOLPHIN protocol ${ }^{25}$ and involved the deletion of the phenylalanine from the DFG loop, along with the next four residues. The deletion of the five residues opens up the space at the entrance to the allosteric site behind the DFG loop, allowing a type-II ligand to occupy both the hinge region of the ATP-binding site and the allosteric site. A key feature, therefore, of the DFG-out structure is the increased overall size of the binding site. Opening of the activation loop also positions the backbone of the aspartic acid of the DFG-in in such a way that allows formation of the "classical" interactions of a type-II inhibitor: (a) one hydrogen bond with the DFG loop Asp, (b) one or two hydrogen bonds with the Glu from the $\alpha \mathrm{C}$-helix, and (c) an interaction with the hinge region. None of the classical type-II interactions will be affected by the five residue deletion, with Asp200, Glu97, and Val135 still available for these hydrogen-bond interactions.

The set of eight ligands shown in Figure 1 was first used for validating the designed type-II models. This set consisted of two known type-II inhibitor scaffolds, sorafenib (three analogues) and doramapimod/BIRB-796 (five analogues), with inhibition data available for both human GSK-3 $\beta$ inhibition and the fungal $U$. maydis GSK- $3 \beta$ isoform. ${ }^{23}$ Results of the Glide-SP docking of these ligands to the DOLPHIN model were encouraging and revealed recognition of the active sorafenib analogues compared to the less-active BIRB-796 analogues in agreement with the experiment (Table $\mathrm{S} 1)$. Additionally, the sorafenib analogue relative potencies $\mathbf{1 b}$ $>1$ c $>1$ la were correctly predicted. The predicted binding of sorafenib (1a) is shown in Figure 2 with the four classical interactions expected of a type-II inhibitor formed. Agreement with the known experimental data, along with the ligands' ability to form all of the classical interactions, led us to decide that the adapted DOLPHIN model was suitable for type-II inhibitor virtual screening.

2.1.2. Prime/Molecular Dynamics Model Creation and Validation. 2.1.2.1. Prime Loop Refinement DFG-Out Structure. The second approach used to design a DFG-out model of GSK- $3 \beta$ involved an initial Prime (activation) loop prediction. $^{28}$ The loop prediction was first trialed on $U$. maydis GSK-3 $\beta$ (UmGSK-3 $\beta)$ for which potent type-II inhibition compared to the human isoform was observed, ${ }^{23}$ suggesting that the DFG-in to DFG-out transformation can be more easily achieved. In agreement, this calculation produced a DFG-out loop conformation with a predicted relative energy of $+4.5 \mathrm{kcal} / \mathrm{mol}$ compared to the top-ranked DFG-in conformation (Figure 3A).

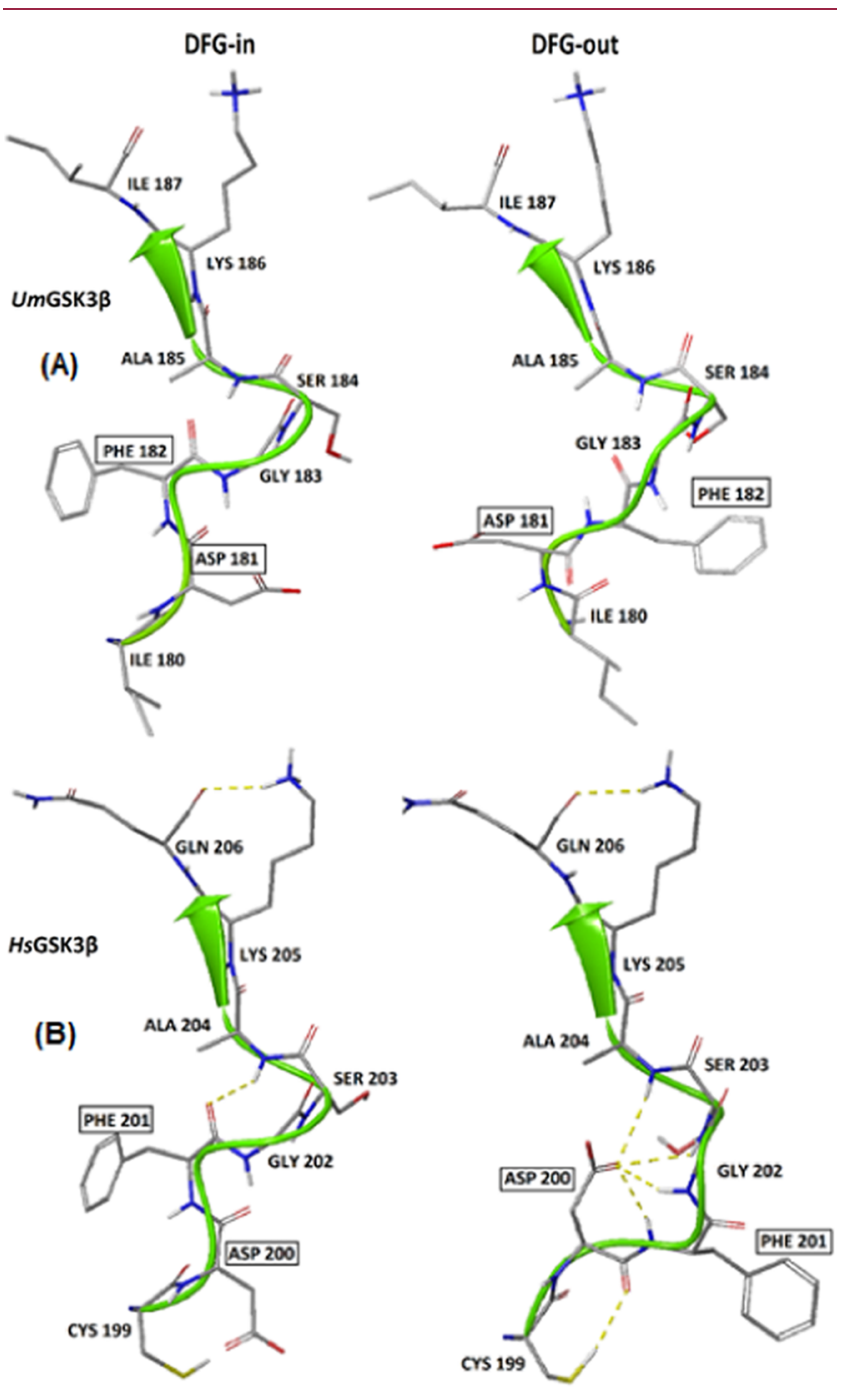

Figure 3. (A) DFG-out activation loop conformation (Prime energy $=-13441.3 \mathrm{kcal} / \mathrm{mol}$ ) of $U$. maydis $(\mathrm{Um}) \mathrm{GSK}-3 \beta$ obtained using Prime loop prediction compared to the DFG-in structure $(-13445.8$ $\mathrm{kcal} / \mathrm{mol})$. (B) DFG-out structure $(-13514.4 \mathrm{kcal} / \mathrm{mol})$ produced by Prime loop prediction of the wild-type human ( $H s)$ GSK-3 $\beta$ compared to the top-scoring DFG-in structure from the same calculation $(-13527.7 \mathrm{kcal} / \mathrm{mol})$. The key Asp and Phe residues involved in the DFG-in to DFG-out transformation in both cases are highlighted. Shape similarity of the activation loops in (A) and (B) for the two isoforms is evident. PDB codes 4E7W (UmGSK-3 $\beta$ ) and 2OW3 $\left(H_{s} \mathrm{GSK}-3 \beta\right)$ were used as the initial starting models for calculations.

However, the same calculation settings for human GSK-3 $\beta$ did not produce a DFG-out conformation. The strong contacts between Gln206 (next to the activation loop) with Lys103 (helix C) and Phe175 (helix E), the equivalent of which is not present in the UmGSK-3 $\beta$ isoform (Figure 4), could inhibit the DFG-in to DFG-out transformation. This 


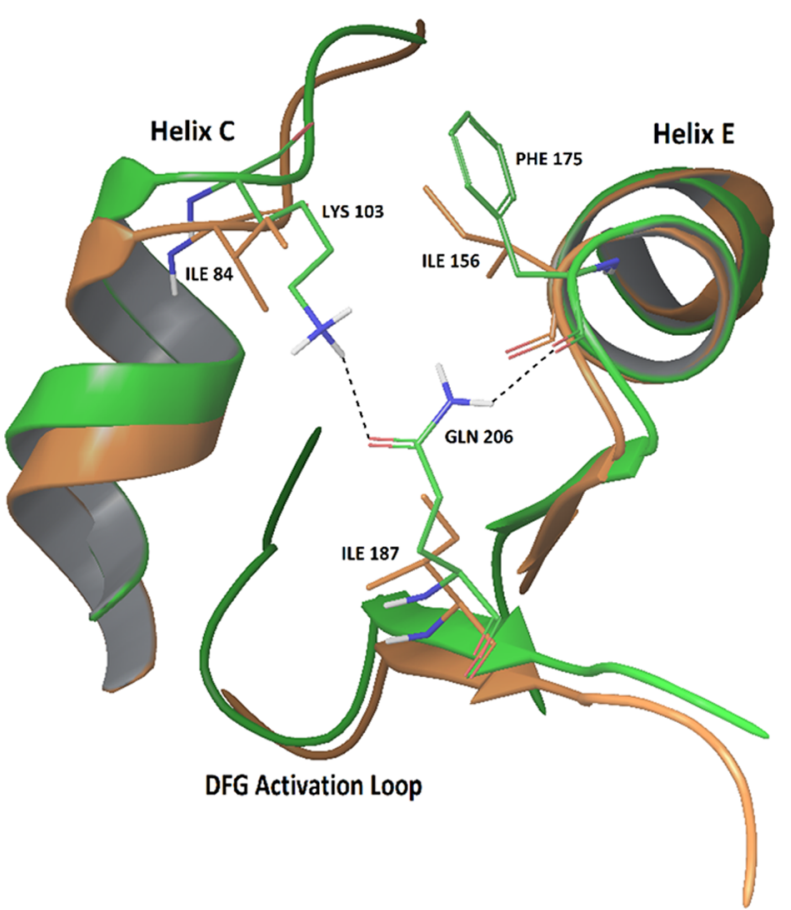

Figure 4. Hydrogen bonding in the human ( $H s)$ GSK-3 $\beta$ (green) DFG-in conformation involving residues Lys103, Gln206, and Phe175 that initially prevented the formation of the DFG-out conformation using Prime loop prediction. Similar strong contacts are absent for the $U$. maydis (Um)GSK- $3 \beta$ isoform (brown). PDB codes 4E7W (UmGSK-3 $\beta)$ and 2OW3 (HsGSK-3 $\beta)$ were used as the initial starting models for calculations.

could also reflect, at least in part, the lower activities of the inhibitors $\mathbf{1 a}-\mathbf{h}$ for human GSK-3 $\beta$ (Figure 1). The Prime loop prediction was repeated with Lys 103 mutated to the equivalent residue type (isoleucine) present in UmGSK-3 $\beta$. This K103I mutation successfully produced the DFG-out conformation (relative energy of $+14.7 \mathrm{kcal} / \mathrm{mol}$ compared to DFG-in). The mutation was then reversed and the calculation repeated, producing the DFG-out structure shown in Figure 3B (relative energy of $+13.3 \mathrm{kcal} / \mathrm{mol}$ compared to the topranked DFG-in structure). In this DFG-out model, the Asp200 side chain has been tucked away into the new shape of the flipped DFG-out loop and forms a number of hydrogen bonds with the loop backbone (Phe201-Ala204). These interactions coupled with the new shape of the activation loop, which is very similar to that of UmGSK-3 $\beta$ (Figure 3), opened the entrance to the allosteric site and created space for type-II inhibitor binding. Induced-fit docking $(\text { IFD })^{30}$ has previously successfully been applied to predict protein-ligand contacts in agreement with the experiment for other challenging cases ${ }^{31-33}$ and was used to further refine this new DFG-out model around a prototype type-II inhibitor, sorafenib (1a). Following the IFD, sorafenib formed all of the classical interactions that type-II ligands are expected to form, and the residues that line the entrance to the allosteric site rearranged to better accommodate the ligand (Figure S1).

2.1.2.2. Molecular Dynamics Simulation Results. To further refine and assess the stability of the generated DFGout protein-ligand (1a) complex, a $20 \mathrm{~ns}$ MD simulation was performed using Desmond. ${ }^{28}$ Equilibration of the system in terms of both backbone and side-chain root-mean-square deviations (RMSDs; Figure S2) was observed, and further analysis of protein-ligand interactions was performed for the last $15 \mathrm{~ns}$ of the simulation.

As can be seen in Figure 2 ( $M D$ representative structure), all type-II inhibition classical interactions are present and were highly conserved ( 90-98\%) throughout the duration of the simulation (Figures 5A and S3), indicative of the stability of
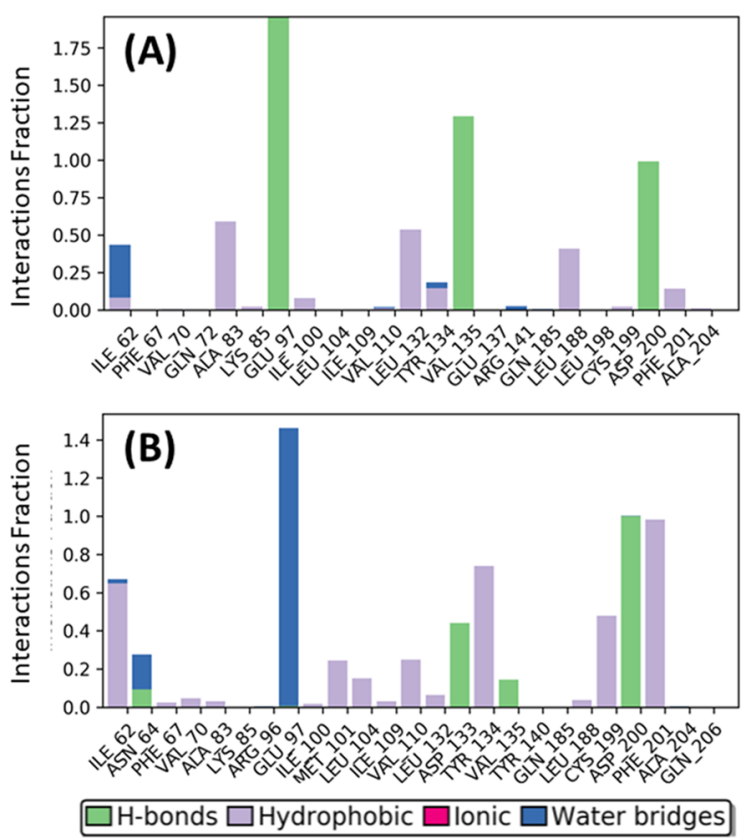

Figure 5. Analysis of the interaction fraction of intermolecular interactions from molecular dynamics simulations of GSK-3 $\beta$ DFGout predicted complexes with (A) sorafenib and (B) the most potent inhibitor from Phase II screening, compound 23. For sorafenib, in terms of the classical type-II interactions, the two ligand urea NHs formed hydrogen bonds to the Glu97 side chain for 0.93 and 0.95 of the simulation (total interaction fraction $=1.88$ ); the urea $\mathrm{O}$ atom was hydrogen-bonded with the Asp200 backbone NH from the DFG loop for 0.98 of the time, and there was a highly conserved hydrogen bond (0.83) with the ATP-binding site hinge region residue Val135. The nature of hydrogen-bond interactions was relatively similar for compound 23 (described in the text), but with Glu97 interactions water-bridged and more favorable hydrophobic interactions, particularly with Ile62, Phe201 (including $\pi-\pi$ stacking), and Tyr134 (cf. also Figure S3).

the DFG-out loop conformation with bound sorafenib. Another noteworthy feature is the interaction with the gatekeeper residue, Leu132. Rather than hinder ligand binding, the small side-chain group of Leu132 forms favorable interactions with the sorafenib phenyl ring, observed $\sim 50 \%$ of the MD duration.

2.1.2.3. Validation of the Prime/Molecular Dynamics Model. Vijayan et al. ${ }^{18}$ performed a detailed analysis of kinase PDB entries, leading to proposals of two distances for classical DFG-out conformations: $D_{1} \leq 7.2 \AA$ between the $C \alpha$ atoms of Asn in the HRDxxxxN motif and Phe in the DFG motif, and $D_{2} \geq 9.0 \AA$ for the $\mathrm{C} \alpha$ atom distance between the conserved Glu belonging to the $\alpha \mathrm{C}$-helix and Phe of the DFG motif. In near agreement, our model had values of 7.3 and $10.4 \AA$ for $D_{1}$ and $D_{2}$, respectively.

The resultant model from Prime/Molecular Dynamics was additionally validated using known inhibition data for sorafenib and BIRB-796 analogues (Figure 1). The results of these Glide-SP docking calculations are shown in Table S1, 

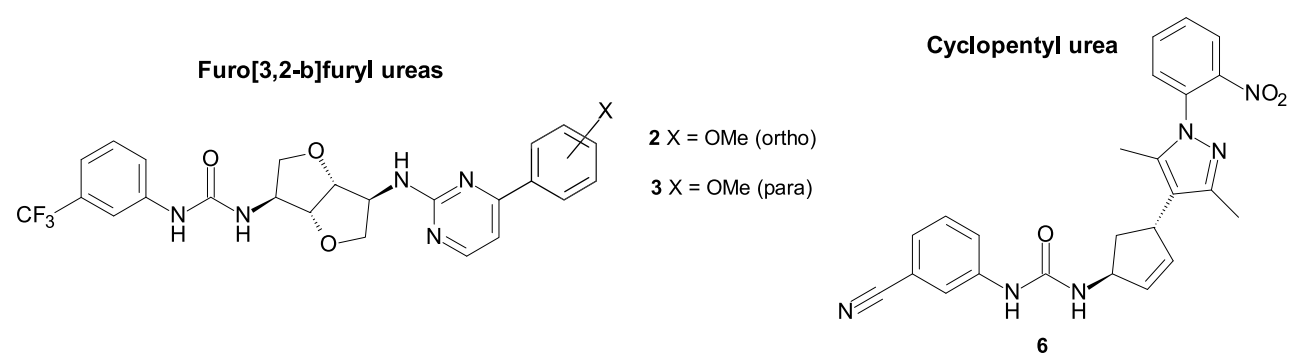<smiles>O=C(NC1=CC=CC(C(F)(F)F)C1)NC1COC2C(OC(=O)Nc3ccc(Oc4ccccc4)cc3)COC12</smiles>

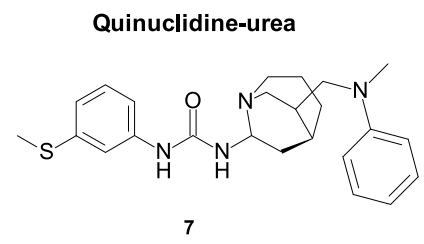<smiles>O=C(Nc1cccc(C(F)(F)F)c1)NC1COC2C(Nn3nnnc3-c3cccc(CN4CCCC4)c3)COC12</smiles>

Oxazino[4,3-a]benzimidazole urea<smiles>COC(=O)c1ccc2c(c1)nc1n2C(NC(=O)Nc2ccccc2)COC1</smiles><smiles>CSCC(=O)N1CC(NC(=O)Nc2cccc(SC)c2)CC1C(=O)NC(Cc1c[nH]c2ccccc12)C(N)=O</smiles><smiles>Cn1cccc1C(=O)N1CC(NC(=O)Nc2ccc(F)cc2F)CC1C(=O)NC(Cc1c[nH]c2ccccc12)C(N)=O</smiles><smiles>CC(C)=CC(=O)N1CC(NC(=O)Nc2ccc(F)cc2F)CC1C(=O)NC(Cc1c[nH]c2ccccc12)C(N)=O</smiles>

1-aralkyl-pyrrolidin-4-yl ethers<smiles>COc1ccc2nc(COC3CN(Cc4cccc5ccccc45)CC3F)[nH]c2c1</smiles>

12<smiles>Cc1cc2nc(COC3CN(Cc4cccnc4)CC3[14CH3])[nH]c2cc1C</smiles><smiles>CC(=O)Nc1ccc(CN2CC(F)C(OCc3nc4cc(C)c(C)cc4[nH]3)C2)cc1</smiles><smiles>COC1CN(Cc2c[nH]c3ccccc23)CC1F</smiles>

13<smiles>[Y17][Y10](=O)O[Na]</smiles>

1-acyl-pyrrolidin-4-yl ethers<smiles>O=C(c1ccncc1)N1CC(F)C(OCc2nc3ccc(F)cc3[nH]2)C1</smiles>

18<smiles>[X]c1ccc(C(=O)N2CC(F)C(OCc3nc4cc(C(F)(F)F)ccc4[nH]3)C2)cc1</smiles>
$19 X=H$
$20 X=O M$<smiles>O=C(c1cccnc1)N1CC(F)C(OCc2nc3cc(C(F)(F)F)ccc3[nH]2)C1</smiles>

21

Figure 6. Structures of the 20 Phase I compounds (2-21) selected for in vitro GSK-3 $\beta$ binding assay experiments, the results of which are shown in Table 1.

and as with the DOLPHIN model, the predicted relative activity of the compounds is in good agreement with the experiment. All sorafenib analogues were again correctly ranked higher than the BIRB-796 compounds (some bias toward sorafenib analogues is possible in this case based on the use of 1a in the DFG-out model design), with each of the 
Table 1. Results of the In Vitro GSK-3 $\beta$ Binding Assay Results Obtained for Phase I (2-21, Figure 6) and Phase II (22-41, Figure 7) Compounds ${ }^{a}$

\begin{tabular}{|c|c|c|c|c|c|c|c|}
\hline \multicolumn{4}{|c|}{ phase I compounds } & \multicolumn{4}{|c|}{ phase II compounds } \\
\hline compound & $\mathrm{IC}_{50}(\mu \mathrm{M})$ & compound & $\mathrm{IC}_{50}(\mu \mathrm{M})$ & compound & $\mathrm{IC}_{50}(\mu \mathrm{M})$ & compound & $\mathrm{IC}_{50}(\mu \mathrm{M})$ \\
\hline 2 & $26.96 \pm 1.77$ & 12 & $>50 \mu \mathrm{M}(13 \%)$ & 22 & $0.56 \pm 0.02$ & 32 & $11.90 \pm 1.57$ \\
\hline 3 & $9.75 \pm 2.2$ & 13 & $>50 \mu \mathrm{M}(14 \%)$ & 23 & $0.087 \pm 0.033$ & 33 & $2.95 \pm 0.45$ \\
\hline 4 & $>50 \mu \mathrm{M}(42 \%)$ & 14 & $>50 \mu \mathrm{M}(5 \%)$ & 24 & $0.412 \pm 0.030$ & 34 & $2.70 \pm 0.15$ \\
\hline 5 & $>50 \mu \mathrm{M}(7 \%)$ & 15 & $>50 \mu \mathrm{M}(2 \%)$ & 25 & $0.421 \pm 0.020$ & 35 & $0.117 \pm 0.028$ \\
\hline 6 & $>50 \mu \mathrm{M}(26 \%)$ & 16 & $>50 \mu \mathrm{M}(2 \%)$ & 26 & $2.06 \pm 0.20$ & 36 & $1.08 \pm 0.17$ \\
\hline 7 & $>50 \mu \mathrm{M}(1 \%)$ & 17 & $>50 \mu \mathrm{M}(19 \%)$ & 27 & $5.66 \pm 0.36$ & 37 & $>50 \mu \mathrm{M}(21 \%)$ \\
\hline 8 & $>50 \mu \mathrm{M}(1 \%)$ & 18 & $>50 \mu \mathrm{M}(19 \%)$ & 28 & $6.08 \pm 0.69$ & 38 & $>50 \mu \mathrm{M}(35 \%)$ \\
\hline 9 & $>50 \mu \mathrm{M}(5 \%)$ & 19 & $>50 \mu \mathrm{M}(7 \%)$ & 29 & $2.08 \pm 0.15$ & 39 & $>50 \mu \mathrm{M}(21 \%)$ \\
\hline 10 & $>50 \mu \mathrm{M}(6 \%)$ & 20 & $>50 \mu \mathrm{M}(33 \%)$ & 30 & $4.042 \pm 0.321$ & 40 & $>50 \mu \mathrm{M}(41 \%)$ \\
\hline 11 & $>50 \mu \mathrm{M}(5 \%)$ & 21 & $>50 \mu \mathrm{M}(14 \%)$ & 31 & $14.05 \pm 1.85$ & 41 & $>50 \mu \mathrm{M}(39 \%)$ \\
\hline
\end{tabular}

$a_{\%}$ Inhibitions at $50 \mu \mathrm{M}$ concentrations are given where relevant. The $\mathrm{IC}_{50}$ of the known type-II inhibitor sorafenib (1a, Figure 1 ) was determined as $32.64 \pm 0.76 \mu \mathrm{M}$ and used as a benchmark for comparison.

analogues predicted to have all classical type-II inhibition interactions. These results, similar to those from the adapted DOLPHIN model, suggested the potential of the model for identification of novel type-II inhibitors.

2.1.3. Virtual Screening Results and Consensus Scoring. Docking calculations of a filtered subset of the ZINC15 biogenic database $^{29}$ (27,286 ligands) using both GSK-3 $\beta$ DFG-out models were performed, and the predicted affinity ranks for both models were combined using a KNIME workflow and the Simple Sum Rank consensus scoring method. $^{34}$ Of the top 200 ranked compounds, 65 had GlideScores similar to the known active sorafenib analogues ( $\leq-9$ for the DOLPHIN model and $\leq-10$ for the Prime/ Molecular Dynamics model) and were chosen for further consideration. Twenty candidates (2-21, Figure 6) from these top 65 were purchased for Phase I in vitro binding assay experiments, together with sorafenib as the benchmark. The compounds were chosen with an emphasis on classical type-II interactions first and then analysis of the additional interactions formed. The selection included diverse scaffolds consisting of [pyrimidin-2-yl] amino-furo[3,2-b]furyl-ureas, a cyclopentyl urea, a quinuclidine urea, and pyrrolidine ureas; also included in this set were some 1-aralkyl-pyrrolidin-4-yl and 1-acyl-pyrrolidin-4-yl ethers. The consensus ranks of these 20 Phase I compounds, as well as their ranks and scores for each of the DFG-out models, are included in Table S2. None of the selected candidate inhibitors, Phase I or II, resulted in warnings for pan assay interference compounds (PAINS) ${ }^{35}$ that often give false-positive results in high-throughput screens, as determined using the ZINC online filter (http:// zinc15.docking.org/patterns/home/).

2.2. In Vitro GSK-3 $\beta$ Binding Assay Results. 2.2.1. Phase I Compounds' Binding Assay Results. The results of the in vitro binding assays against human GSK-3 $\beta$ for the initial Phase I 20 selected compounds (Figure 6) are summarized in Table 1 . The percentage inhibition of GSK-3 $\beta$ at $50 \mu \mathrm{M}$ concentrations was first determined, and for those compounds with $>50 \%$ inhibition, $\mathrm{IC}_{50}$ values were determined.

Compounds 2-21 resulted in a percentage inhibition of GSK-3 $\beta$ ranging from $\sim 1$ to $90 \%$ at $50 \mu \mathrm{M}$ concentration. Two low micromolar hit compounds $2\left(\mathrm{IC}_{50}=26.96 \mu \mathrm{M}\right)$ and $3\left(\mathrm{IC}_{50}=9.75 \mu \mathrm{M}\right)$ were identified, both [pyrimidin-2yl] amino-furo[3,2-b] furyl-ureas, that had $\mathrm{IC}_{50}$ values better than the sorafenib benchmark compound $\left(\mathrm{IC}_{50}=32.64 \mu \mathrm{M}\right)$.
The predicted binding modes of $\mathbf{2}$ and 3 were similar and are shown in Figure $7 \mathrm{~A}, \mathrm{~B}$, respectively. All classical type-II inhibitor interactions are present. In the hinge region, there are hydrogen-bonding interactions with both Val135 and Asp133 backbones. Structurally, the two ligands only differ in the positioning of a methoxy phenyl ring substituent, with a parasubstitution favored. In terms of the two GSK-3 $\beta$ DFGout models used in the in silico screening, the Prime/MD model ranked the more potent compounds higher (Table S2) and the Phase II compound selection was weighted accordingly.

2.2.2. Phase /I Compounds' Binding Assay Results. Based on the results of Phase I screening of compounds and the identification of the [pyrimidin-2-yl] amino-furo[3,2-b]furylureas as a hit scaffold, it was decided to perform a focused SAR analysis on modifications of the hit structures. As a result, 20 further compounds (22-41) were selected for Phase II in vitro binding assay experiments, which included a range of different substitutions at different positions (Figure 8), including exploration of different furo[3,2-b]furyl ring atom configurations for compounds 36-41. The GlideScores and predicted rankings of these ligands in the original in silico screening are included in Table S3, the majority of which (17) were ranked in the top 500 compounds using the Prime/MD DFG-out model.

The results of the Phase II GSK- $3 \beta$ binding assay experiments are displayed in Table 1 . These new experiments revealed a number of very potent inhibitors, with the best compound 100 times more potent than its Phase I equivalent (3). Five of the compounds (22-25 and 35) were in the nanomolar range, with eight new low micromolar inhibitors identified. The most potent compounds were $23\left(\mathrm{IC}_{50}=\right.$ $0.087 \mu \mathrm{M})$ and $35\left(\mathrm{IC}_{50}=0.117 \mu \mathrm{M}\right)$. A 100 ns $\mathrm{MD}$ simulation was used to further explore the binding of the most potent inhibitor 23 (cf. also. mp4, Supporting Information). Similar protein-ligand interactions to those observed in the preliminary docking screening (Figure S4) were observed, with an MD representative model shown in Figure $7 \mathrm{C}$; the interaction fractions from the simulation are shown in Figure 5B. There are strong direct hydrogen-bond contacts $(100 \%$ duration) with the Asp200 backbone NH from the DFG-out loop; hinge region hydrogen bonds involving the inhibitor 2aminopyrimidine group with Asp133 (44.2\% duration) and Val135 (14.3\% duration). Compared to sorafenib (Figure 5A), there are more favorable hydrophobic contact interactions in 

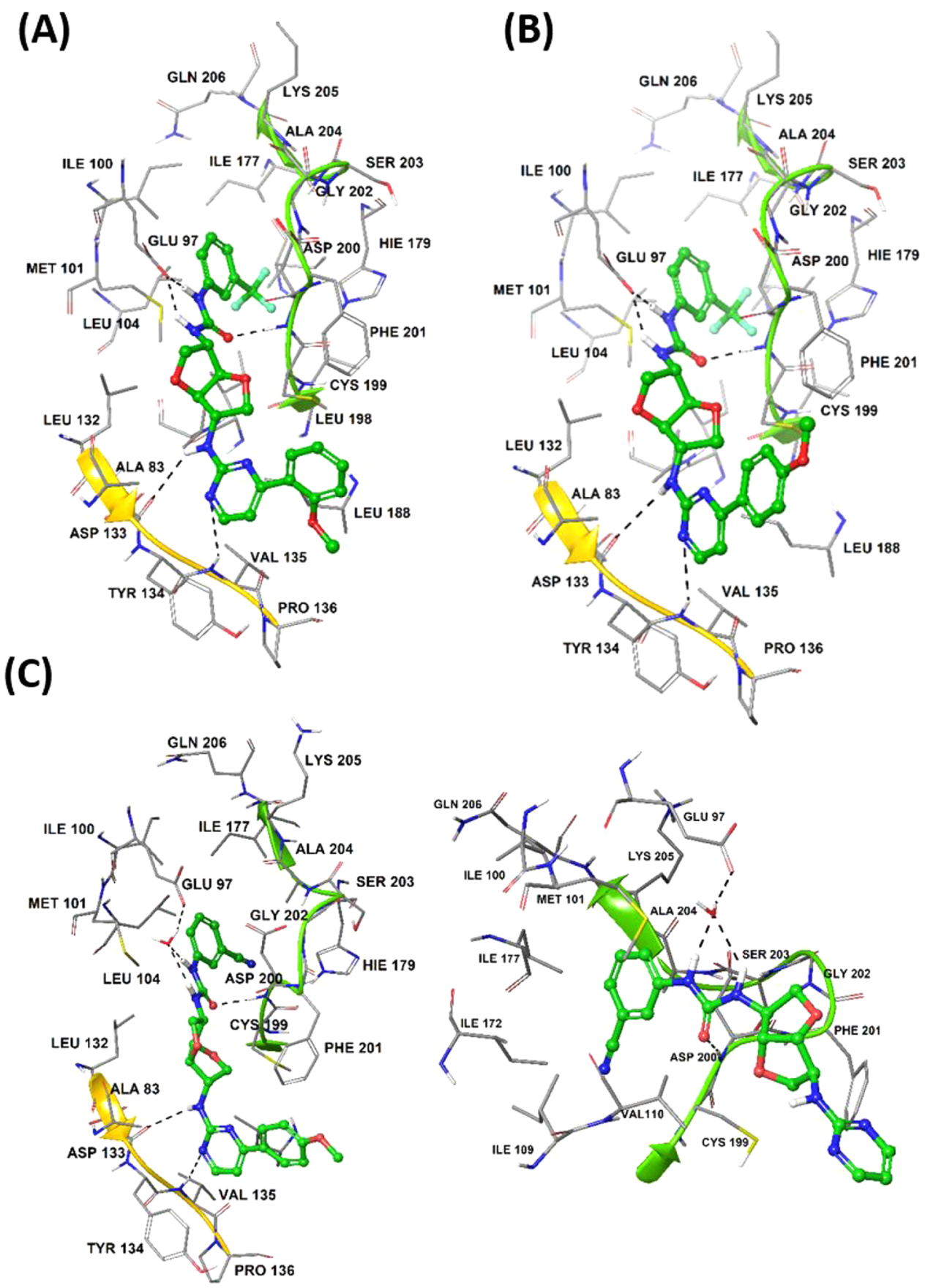

Figure 7. Predicted binding interactions from Glide-SP docking to the Prime/MD representative GSK- $3 \beta$ model of the most potent inhibitors from the Phase I compounds (A) $2\left(\mathrm{IC}_{50}=26.96 \mu \mathrm{M}\right)$ and (B) $3\left(\mathrm{IC}_{50}=9.75 \mu \mathrm{M}\right)$, as well as the representative protein-ligand structure from $\mathrm{MD}$ simulations of the most potent nanomolar inhibitor from Phase II compounds, (C) $23\left(\mathrm{IC}_{50}=0.087 \mu \mathrm{M}\right.$ ). For compounds 23 , the interactions in the allosteric pocket of the DFG-out conformation are also separately highlighted, with the phenyl CN substituent of 23 buried between three hydrophobic side chains of residues Ile109, Ile172, and Leu198. Protein-ligand hydrogen bonds are displayed as black dashed lines. PDB code $2 \mathrm{OW} 3$ was used as the initial starting model for calculations.

the allosteric hydrophobic pocket (Met101; Leu104) and through interactions with the $p$-methoxy-phenyl group (Ile62; Phe201) (cf. also Figure S3). The inhibitor methoxy $\mathrm{O}$ atom is also involved in hydrogen-bond interaction, direct (9.3\% duration) or water-bridged (18.2\% duration), with Asn64. The key difference in the MD representative compared to docking prediction (and sorafenib binding) is that interactions with Glu97 are predicted to be predominantly water-bridged as opposed to direct but are almost present throughout. As this is a model, it is still possible that these hydrogen bonds may in fact be direct, as predicted from docking (Figure S4).

Using $3\left(\mathrm{IC}_{50}=9.75 \mu \mathrm{M}\right)$ as a basis for SAR analysis (Figure 8), we first investigated substitutions at different positions of both terminal phenyl rings ( 1 and $\underline{2})$ through compounds 22-29. Keeping the $-\mathrm{OMe}$ (para) on phenyl $\underline{1}$ fixed as in compound 3 and exploring $\mathrm{X}_{2}$ substitutions (phenyl 2) revealed four nanomolar inhibitors, 22 with $\mathrm{X}_{2}=\mathrm{H}\left(\mathrm{IC}_{50}=\right.$ $0.560 \mu \mathrm{M})$, 24 with $\mathrm{X}_{2}=\mathrm{C}(\mathrm{O}) \mathrm{Me}($ para $)\left(\mathrm{IC}_{50}=0.412 \mu \mathrm{M}\right)$, 23 with $\mathrm{X}_{2}=\mathrm{CN}$ (meta) $\left(\mathrm{IC}_{50}=0.087 \mu \mathrm{M}\right)$, and 25 with $\mathrm{X}_{2}$ 

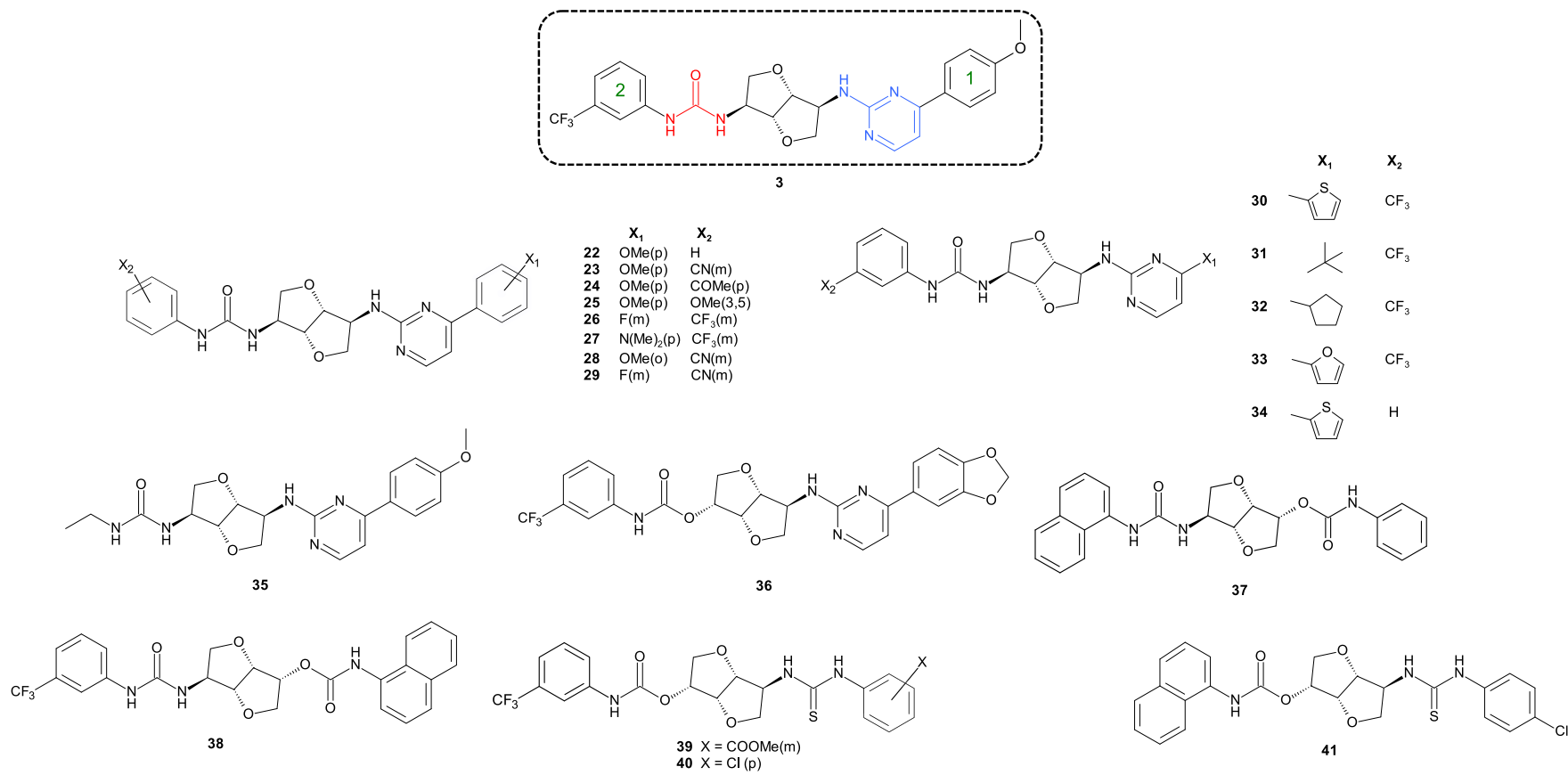

Figure 8. Phase II selection of compounds (22-41) for in vitro GSK-3 $\beta$ binding assay experiments. The most potent inhibitor (3) from Phase I is highlighted as a basis for SAR analysis.

$=\operatorname{OMe}(3,5)\left(\mathrm{IC}_{50}=0.421 \mu \mathrm{M}\right)$. Hence, a $-\mathrm{CN}$ (meta) substitution was particularly effective (Figure 7C).

With either $\mathrm{X}_{2}=\mathrm{CF}_{3}$ (meta) or $\mathrm{CN}$ (meta) and instead exploring $\mathrm{X}_{1}$ substitutions (phenyl 1 ) resulted in less potent but still low micromolar inhibitors (26-29), highlighting the importance of the $\mathrm{X}_{1}=\mathrm{OMe}$ (para) substituent of the nanomolar compounds, which formed the aforementioned hydrogen-bond interactions with Asn64 in the MD simulation for compound 23 (Figures 5B and S3). Additionally, having an ethyl group $\left(35, \mathrm{IC}_{50}=0.117 \mu \mathrm{M}\right)$ instead of the phenyl $\underline{2}$ group also revealed nanomolar potency; predicted binding from the Prime/MD representative model docking is shown in Figure S4.

Compounds 30, 32, and 33 investigated replacements of the phenyl 1 substituent of the pyrimidine of 3 with different five-membered rings $\left(\mathrm{X}_{1}\right.$ substitutions), and 31 investigated replacement with an isopropyl group. This had a modest effect on potency with all compounds demonstrating low micromolar potency, the best of which (33, furan ring substituent) had an $\mathrm{IC}_{50}$ of $2.95 \mu \mathrm{M}$. Replacing the $\mathrm{X}_{2}=\mathrm{CF}_{3}$ group of 30 $\left(\mathrm{IC}_{50}=4.04 \mu \mathrm{M}\right)$ with a hydrogen $\left(34 ; \mathrm{IC}_{50}=2.70 \mu \mathrm{M}\right)$ had little effect on potency.

Substitution of the urea group (red, Figure 7) of 3 with a $-\mathrm{NHC}(\mathrm{O}) \mathrm{O}-$ linker together with a change of configuration in the furo[3,2-b]furyl ring for $\mathbf{3 6}$ led to reduced hydrogenbond contact to Glu97 from docking predictions, but together with the effects of fusing the phenyl at ring position $\underline{1}$ with a 1,3-dioxolane still resulted in low micromolar inhibition $\left(\mathrm{IC}_{50}\right.$ $=1.08 \mu \mathrm{M})$. Significantly, replacement of the 2-aminopyrimidine substituent of 3 (blue, Figure 7) with other entities and different configurations of the furo[3,2- $b]$ furyl ring (compounds 37-41) all led to loss of hinge region interactions resulting in poor inhibition $\left(\mathrm{IC}_{50}>50 \mu \mathrm{M}\right)$.

2.3. Kinase Selectivity Screen. To probe the potential selectivity of the new potent compounds for GSK-3 $\beta$ inhibition, selectivity screening of the nanomolar inhibitors 23 and 24 against 11 other kinases (CDK2, CDK5, CDK9,
ERK1, ERK2, PKA, PKB $\alpha, \operatorname{PKB} \beta, \operatorname{PKC} \alpha, \mathrm{PKC} \gamma$, and GSK$3 \alpha$ ) was performed, with the results shown in Figure 9. The results of this single-dose profiling $(5 \mu \mathrm{M})$ revealed significant selectivity toward GSK-3 $\beta$ inhibition over the other enzymes. The most potent GSK-3 $\beta$ inhibitor 23 was highly selective for
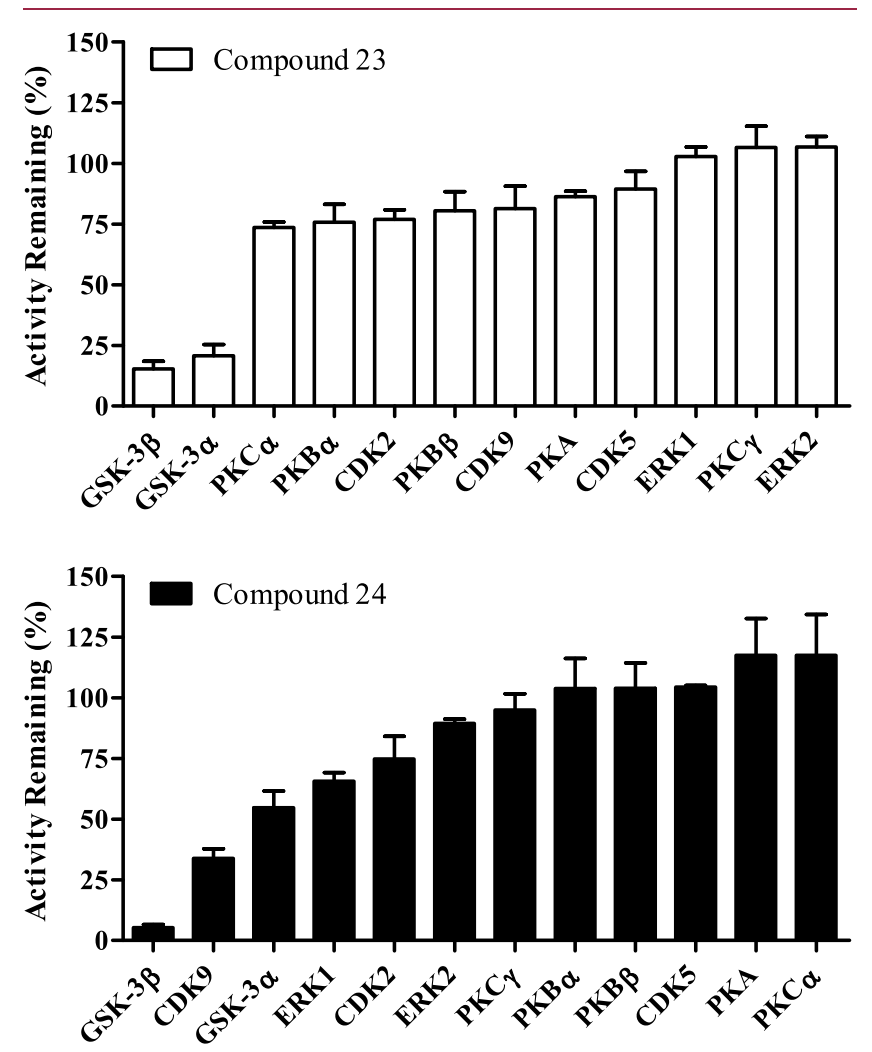

Figure 9. Single-dose $(5 \mu \mathrm{M})$ selectivity profile of GSK-3 $\beta$ nanomolar inhibitors 23 and 24 versus 11 homologous kinases shown as the \% remaining activity \pm standard deviation. 
A. TDZD-8

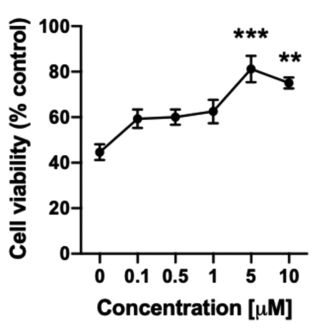

F. compound 26

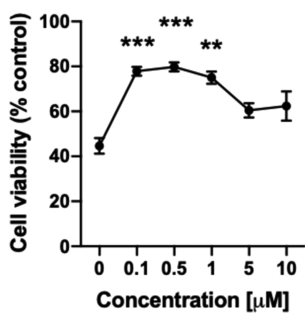

B. compound 22

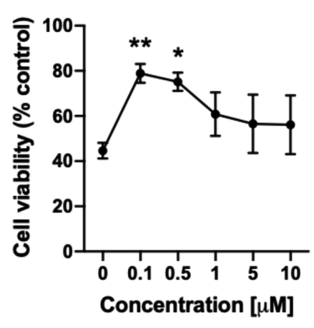

G. compound 28

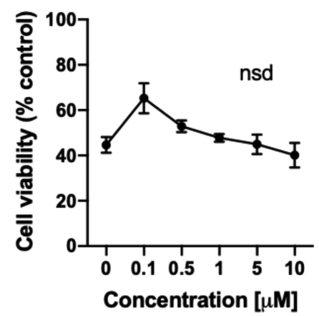

C. compound 23

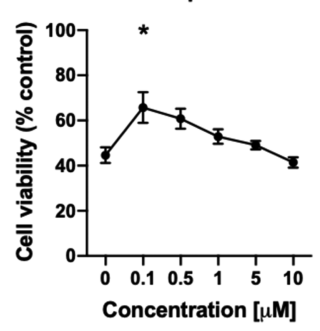

H. compound 29

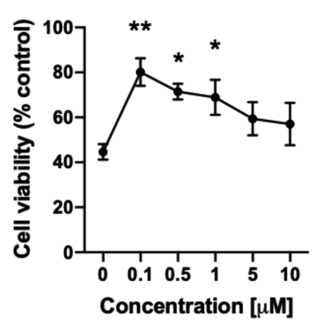

D. compound 24

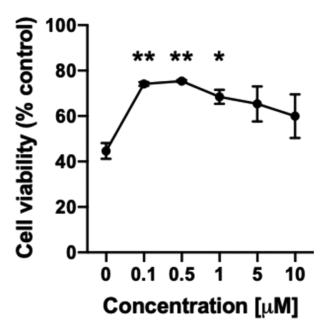

I. compound 35

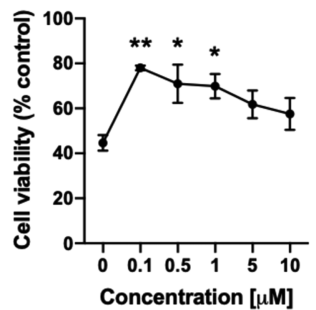

E. compound 25

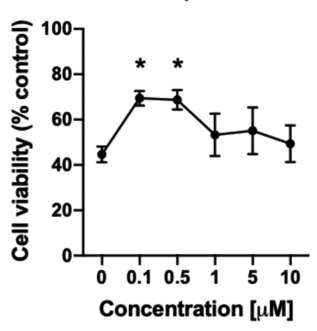

J. compound 36

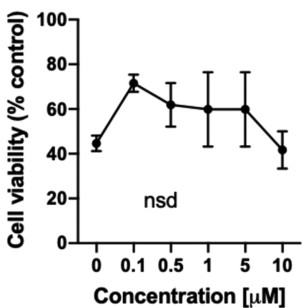

Figure 10. Effects of identified GSK-3 $\beta$ inhibitors 22-26, 28-29, and 35-36 on an okadaic acid-induced neurodegeneration cell model. The efficacies of five different inhibitor concentrations were tested $(0.1,0.5,1,5$, and $10 \mu \mathrm{M})$, with TDZD-8 used as a benchmark inhibitor for comparison. Okadaic acid caused a significant reduction in cell viability (to $43.08 \%$ of the control values, $\mathrm{T}(194)=14.98, P<0.0001$; data not shown). The data presented in the graph are cell viability as a percentage of the control. In all cases, okadaic acid is present at $30 \mu \mathrm{M}$. Data are the mean \pm standard error of mean (SEM) of three independent experiments at each test compound concentration. Cell line: SH-SY5Y. Data in each panel (A-J) were analyzed using a one-way analysis of variance (ANOVA) with post hoc analysis with the Bonferroni test versus okadaic acid. $* p<0.05 ; * * p<0.01$; and $* * * p<0.001$ significant difference versus okadaic acid alone. Nsd, no significant difference.

GSK-3 $\beta$ compared to the other kinases and also demonstrated slight selectivity for GSK-3 $\beta$ inhibition over its GSK-3 $\alpha$ isoform. Compound 24, which demonstrated a better profile in the cell viability experiments (vide infra), had better selectivity for GSK-3 $\beta$ over GSK-3 $\alpha$; all other enzymes had $>50 \%$ remaining activity with the exception of CDK9 (33.8\%). CDK9 plays a key role in inflammation, with neuroinflammation a hallmark of neurological disorders. Moreover, dual GSK-3 $\beta /$ CDK9 inhibitors have shown interesting antinflammatory and anticancer profiles both in vitro and in vivo. ${ }^{36}$

2.4. Ex Vivo Experiments: Tau Hyperphosphorylation. Nanomolar (22-25 and 35) along with four low micromolar $(26,28,29$, and 36) inhibitors from Phase II screening progressed to ex vivo experiments. The okadaic acid (OA)-induced neurodegeneration cell model was used to explore the anti-tau profile of the GSK-3 $\beta$ inhibitors in comparison with the well-known GSK-3 $\beta$ inhibitor TDZD$8,{ }^{37}$ structurally similar to the previous $\mathrm{AD}$ clinical trial candidate, tideglusib. ${ }^{38}$ OA-treated cell lines and primary neuronal cultures have been used as established cellular models of hyperphosphorylated tau-induced neurodegeneration. $^{39,40}$ The phosphorylation of tau by GSK-3 $\beta$ and its relation to formation of neurofibrillary tangles have been welldocumented $^{41-43}$ and the reduction of phosphorylated tau by GSK- $3 \beta$ inhibition has been demonstrated, ${ }^{44,45}$ and thus neuroprotective effects of the compounds in the experiments can be most likely mainly attributed to their potent inhibition of GSK-3 $\beta$.

We studied the effects of the chosen compounds at five different concentrations (Figure 10). As expected, OA induced a decrease in cell viability of more than $50 \%$. These data show that the test compounds all inhibit the toxic effects of okadaic acid except compounds 28 (Figure 10G) and 36 (Figure 10J). Of the active compounds, they were all protective at lower concentrations than our benchmark compound TDZD-8, with all test compounds (except 28 and 36) active at the lowest concentration tested $(0.1 \mu \mathrm{M})$. Compounds 24 (Figure 10D), 26 (Figure 10F), 29 (Figure 10H), and 35 (Figure 10I) appear to have the best profile, being active at the three lowest concentrations. The GSK- $3 \beta$ inhibitory potencies cannot be accurately correlated with the functional effects seen in Figure 10. This could at least in part be attributed to the relative similarities of the GSK-3 $\beta$ inhibitor potencies together with potential differences in their pharmacokinetic properties.

\section{CONCLUSIONS}

GSK- $3 \beta$ is an important target for the development of muchneeded new treatments for $\mathrm{CNS}$ disorders such as $\mathrm{AD}$. We have explored, for the first time, the design of ligands to stabilize the DFG-out conformation of the enzyme in a type-II inhibition mechanism. For this purpose, two different type-II DFG-out models (adapted DOLPHIN and Prime/MD) were used for Glide-SP virtual screening of 27,286 natural product derivatives. Candidates from this were selected for in vitro GSK- $3 \beta$ binding assay experiments in two phases, Phase I and Phase II. Phase I results revealed two low micromolar inhibitors, $2\left(\mathrm{IC}_{50}=27 \mu \mathrm{M}\right)$ and $3\left(\mathrm{IC}_{50}=9.8 \mu \mathrm{M}\right)$, both of which had a [pyrimidin-2-yl] amino-furo[3,2-b] furyl-urea scaffold. Selection of 20 more analogues based on this scaffold for Phase II experiments revealed five highly potent inhibitors (22-25 and 35) on the nanomolar range and eight additional low micromolar inhibitors. Compared to the DOLPHIN structure, the Prime/MD DFG-out model generally ranked the potent inhibitors higher, highlighting the potential of the model for identification of other hit compounds with different chemical scaffolds using virtual screening. Kinase selectivity profiling for compounds 23 and 24 against 11 homologous kinases revealed good selectivity for GSK-3 $\beta$ inhibition. Additionally, some of the most potent inhibitors demonstrated 
neuroprotective effects in an OA-induced neurodegeneration cell-based model with efficacy greater than that of the standard reference TDZD-8 at low micromolar concentrations. [pyrimidin-2-yl]amino-furo[3,2-b]furyl-ureas have therefore been identified as a privileged scaffold for the development of GSK-3 $\beta$ and potentially other kinase type-II inhibitors. This study has also unraveled the unexplored potential for the design of more effective GSK-3 $\beta$ inhibitors (selective, longer duration of action) targeting a type-II mechanism. ${ }^{46,49}$ The potential for type-II inhibition with other kinases may be performed in a similar manner, given that the type-II inhibition phenomenon might extend to a wide range of kinases.

\section{EXPERIMENTAL SECTION}

4.1. Computational Methods. 4.1.1. Ligand Preparation. All ligands were prepared for docking using Maestro and LigPrep v3.6 at a $\mathrm{pH}$ of $7.0 \pm 1.0$. The Biogenics subset from the ZINC15 database $^{29}$ was downloaded for the virtual screening, with the purchasable filter applied. ADMET-predicted properties from QikProp $4.6^{28}$ in the standard mode were used to filter the compounds based on a previous property analysis of 30 diverse ATPbinding site (type-I) GSK-3 $\beta$ inhibitors from clustering of nanomolar potency compounds (M.P. Davies, unpublished): $200 \leq \mathrm{MW} \leq 650$ $\mathrm{Da}, 0 \leq \log \mathrm{P}$ o/w $\leq 5$, hydrogen-bond acceptors (HBAs) $\leq 11$, hydrogen-bond donors (HBDs) $\leq 6$. Too much flexibility hinders permeability, so that the number of rotatable bonds $\leq 10$ based on Veber's rules was applied. ${ }^{48}$ The final screening set consisted of 27286 ligands, or 45092 including the different tautomers and ionization states.

4.1.2. Protein Preparation (DFG-in). The initial preparation of GSK-3 $\beta$ for calculations was performed using Schrödinger's Protein Preparation Wizard ${ }^{28}$ and the protein from PDB code 2OW3 $(2.8 \AA$ resolution). ${ }^{49}$ 2OW3 was chosen due to its more open binding site bound to a bis-(indole) maleimide pyridinophane inhibitor and previous successes in type-I inhibitor screening; ${ }^{50}$ the more open binding site was also determined as more suitable in initial trials for generating DFG-out models (compared to the PDB code 1H8F). Water molecules within $5 \AA$ of the ligand were initially retained but deleted for subsequent calculations. Bond orders were assigned and hydrogen atoms added, with protonation states for basic/acidic residues based on calculated residue $\mathrm{p} K_{\mathrm{a}}$ values from PROPKA ${ }^{51}$ at normal $\mathrm{pH}$ (7.0). Subsequent optimizations of hydroxyl groups, histidine protonation states, and $\mathrm{C} / \mathrm{N}$ atom "flips" and side-chain $\mathrm{O} /$ $\mathrm{N}$ atom flips of Asn and Gln residues were based on optimizing hydrogen-bonding patterns. Finally, an Impref minimization of the $\mathrm{GPb}$ complex was performed using the OPLS3 forcefield ${ }^{52}$ to remove any steric clashes and bad contacts. At the end of the minimization, the RMSD of all heavy atoms was within $0.3 \AA$ of the crystallographic positions. The preparation of $U$. maydis GSK-3 $\beta$ (PDB code 4E7W; $3.3 \AA$ resolution $)^{23}$ was performed in a similar manner.

4.1.3. DOLPHIN Docking Details. For creation of the adapted DOLPHIN GSK- $3 \beta$ model, the phenylalanine of the DFG loop (Phe201) was selected and deleted, along with the next four residues (202-205). The use of a similar approach in the original paper yielded consistent results with the full DOLPHIN/pharmacophore field approach. ${ }^{25}$ An initial Glide $7.2^{28}$ grid $(29.5 \AA \times 29.5 \AA$ × 29.5 $\AA$ ) for positioning of the type-II ligand sorafenib (1a) into the site was achieved using the center of hinge region residues Asp133Val135 and DFG loop Asp200. Using the docked model of 1a, a new docking grid was calculated centered on 1a and used for the validation of the model and the subsequent virtual screening. Glide in the SP mode was used for all docking calculations and incorporated postdocking minimization with strain correction. Standard parameters were otherwise applied, including default OPLS3 atomic charges and van der Waals scaling (0.8) for ligand nonpolar atoms to include modest "induced-fit" effects.
4.1.4. Prime/Molecular Dynamics Model. 4.1.4.1. Activation Loop Refinement. The prepared DFG-in GSK-3 $\beta$ structure (4.1.2) was used in Prime 4.5 loop refinement calculations ${ }^{28}$ in attempts to generate a DFG-out model. To achieve this, the calculations were performed on wild-type GSK-3 $\beta$ and a K103I mutated form, as outlined in the results. The calculation settings incorporated the use of VSGB implicit solvation, ${ }^{53}$ which is based on the surfacegeneralized Born (SGB) model and the variable dielectric (VD) treatment of polarization from protein side chains, the OPLS3 forcefield, ${ }^{52}$ and with the activation loop residues 199-204 selected for refinement.

4.1.4.2. Induced-Fit Docking. IFD calculations ${ }^{28}$ of sorafenib (1a) to the DFG-out model generated from the Prime loop refinement were performed. The docking grid of dimensions $29.5 \AA \times 29.5 \AA \times$ $29.5 \AA$ was centered on the sorafenib pose from the DOLPHIN calculations, superimposed into the site. IFD calculations consisted of three stages. In Stage I, initial Glide 7.2 SP docking ${ }^{24,28}$ was performed, with a maximum of 20 poses saved. To increase the size of the binding pocket, two residues (Met101 and Asp200) were selected for mutation to Ala during this initial docking (rebuilt in Stage II). In Stage II, protein residues within $7 \AA$ of the initial protein-ligand poses were refined using Prime $4.5 .^{27,28}$ Finally in Stage III, up to 20 structures from Stage II within $30 \mathrm{kcal} / \mathrm{mol}$ of the lowest energy structure were used for Glide-SP ligand redocking calculations. The final protein-ligand geometries were analyzed in terms of structure and binding interactions, as well as the IFDScores (redocking Glidescore $+5 \%$ Prime energy).

4.1.4.3. MD Refinement. The top-scoring GSK-3 $\beta$-sorafenib complex structure from the IFD calculations was used as input for MD using Desmond v3.6. ${ }^{28}$ The initial setup for simulation involved soaking the system with a pre-equilibrated TIP3P model orthorhombic water box with side lengths as follows: side $a=$ $83.98 \AA$, side $b=87.25 \AA$, side $c=72.34 \AA$ and volume $530034 \AA^{3}$, allowing a $10 \AA$ buffer region between the protein and box sides and neutralizing the system with six $\mathrm{Cl}^{-}$ions. This setup procedure produced 15,064 water molecules with the final system consisting of 50907 atoms. Heavy-atom bond lengths with hydrogens and the internal geometry of water molecules were constrained using the SHAKE algorithm. Atom types and forcefield parameters from $\mathrm{OPLS}^{52}$ were assigned to the system. Periodic boundary conditions (PBCs) were applied and a cutoff of $9.0 \AA$ was used for nonbond interactions, with electrostatic interactions treated using the particle mesh Ewald (PME) method. ${ }^{54}$ The default standard Desmond relaxation and equilibration protocol was employed, followed by a 20 ns production run in the NPT ensemble $(T=300 \mathrm{~K}$, thermostat relaxation time $=1.0 \mathrm{ps}, P=1 \mathrm{~atm}$, barostat relaxation time $=2.0 \mathrm{ps})$ using a Nose-Hoover thermostat and the Martyna-Tobias-Klein barostat. ${ }^{55,56}$ A multiple-time-step RESPA integration algorithm was used with time steps of 2, 2, and 6 fs for bonded, "near" nonbonded, and "far" nonbonded interactions, respectively. Energy and trajectory atomic coordinate data were collected every 1.2 and 5.0 ps, respectively. Visualization and analysis of the MD trajectory were performed employing Desmond Maestro's simulation analysis tools. Employing Maestro's Desmond trajectory clustering tool and the hierarchical cluster linkage method, clustering of 4000 trajectory frames from the last $15 \mathrm{~ns}$ (ligand and protein residues within $7 \AA)^{57}$ into 10 clusters based on atomic RMSDs was performed and a representative structure was taken from the most populated cluster to be used as the final DFG-out model.

4.1.4.4. Docking Details. For the docking calculations, the representative structure from the $\mathrm{MD}$ was used and the same settings as those described in 4.1.3 for DOLPHIN docking were applied, with the docking grid $(29.5 \AA \times 29.5 \AA \times 29.5 \AA)$ centered on the bound sorafenib (1a) ligand.

4.1.5. Molecular Dynamics GSK-3 $\beta$-Compound 23 Complex. The predicted GSK-3 $\beta$ DFG-out complex with compound 23 from docking to the Prime/MD model was used as input for MD simulation using Desmond v3.6. System setup details were as indicated for the corresponding Prime/MD simulation above, but in this case, the orthorhombic box had dimensions $a=90.94 \AA, b=$ 
$71.05 \AA$, and $c=79.42 \AA$ (volume 513,164 $\AA^{3}$ ), including 14,444 water molecules, and the final systems consisted of 49,058 atoms. The relaxation protocol was as previously described, as was the production run, except in this case an extended $100 \mathrm{~ns}$ MD simulation was performed. Desmond trajectory clustering was again used to obtain a representative model of the protein-ligand complex: frames from the last $60 \mathrm{~ns}$ of the simulation (ligand and protein residues within $7 \AA$ ) were clustered into 10 groups, and the representative structure from the largest cluster was taken.

4.2. Experimental Details. 4.2.1. In Vitro GSK-3 $\beta$ Binding Assays. All predicted inhibitors for testing were from Analyticon Discovery, Germany. The purity data is included in the Supporting Information. Purity of all screening compounds was at least $85 \%$ based on ${ }^{1} \mathrm{H}$ NMR and high-performance liquid chromatography (HPLC) by absorbance at $215 \mathrm{~nm}$ wavelength. The purity of all

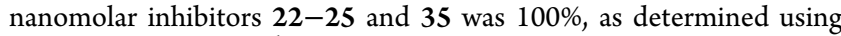
HPLC-MS-DAD and ${ }^{1} \mathrm{H}$ NMR. High-performance liquid chromatography equipped with single quadrupole mass spectrometry, diode array, and evaporative light-scattering detectors (HPLC-MS-PDAELSD) was carried out on a Shimadzu LC-20 AD XR using GeminiNX C18 $3 \mu \mathrm{M}, 3 \mathrm{~mm} \times 50 \mathrm{~mm}$ reverse-phase column, eluted with a 6 min gradient system of 5:95 to 100:0 methanol/water, consisting of a buffer of $5 \mathrm{mM}$ ammonium bicarbonate adjusted to $\mathrm{pH} 10.4$ with ammonia, at a flow rate of $1.2 \mathrm{~mL} / \mathrm{min}$. Mass spectra (MS) were performed using positive and negative electrospray ionization (ESI). NMR spectra were measured on a Bruker $500 \mathrm{MHz}$ NMR instrument. Sorafenib was purchased from Key Organics U.K. Human recombinant GSK-3 $\beta$ and the prephosphorylated polypeptide substrate were purchased from Millipore (Millipore Iberica SAU). Kinase-Glo Luminescent Kinase Assay was obtained from Promega (Promega Biotech Iberica, SL). ATP and all other reagents were from Sigma Aldrich (St. Louis, MO). The assay buffer contained 50 $\mathrm{mM}$ HEPES ( $\mathrm{pH}$ 7.5), $1 \mathrm{mM}$ ethylenediaminetetraacetic acid (EDTA), $1 \mathrm{mM}$ ethylene glycol-bis(2-aminoethylether)- $N, N, N^{\prime}, N^{\prime}$ tetraacetic acid (EGTA), and $15 \mathrm{mM}$ magnesium acetate. The method of Baki et al. was followed to analyze the inhibition of GSK$3 \beta .^{58}$ Kinase-Glo assays were performed in an assay buffer using black 96-well plates. In a typical assay, $10 \mu \mathrm{L}(10 \mu \mathrm{M})$ of the test compound [dissolved in dimethyl sulfoxide (DMSO) at $1 \mathrm{mM}$ concentration and diluted in advance in an assay buffer to the desired concentration] and $10 \mu \mathrm{L}(20 \mathrm{ng})$ of the enzyme were added to each well followed by $20 \mu \mathrm{L}$ of assay buffer containing $25 \mu \mathrm{M}$ substrate and $1 \mu \mathrm{M}$ ATP. The final DMSO concentration in the reaction mixture did not exceed $1 \%$. After $30 \mathrm{~min}$ incubation at $30{ }^{\circ} \mathrm{C}$, the enzymatic reaction was stopped with $40 \mu \mathrm{L}$ of Kinase-Glo reagent. Glow-type luminescence was recorded after $10 \mathrm{~min}$ using a FLUOstar Optima (BMG Labtechnologies GmbH, Offenburg, Germany) multimode reader. The activity is proportional to the difference of the total and consumed ATP. The inhibitory activities were calculated based on maximal activities measured in the absence of an inhibitor. The $\mathrm{IC}_{50}$ was defined as the concentration of each compound that reduces $50 \%$ of the enzymatic activity with respect to that without inhibitors.

4.2.2. Kinase Selectivity Screening. Selected compounds were assayed in duplicate at a single concentration $(5 \mu \mathrm{M})$ against CDK2, CDK5, CDK9, ERK1, ERK2, PKA, PKB $\alpha, \operatorname{PKB} \beta, \operatorname{PKC} \alpha, \operatorname{PKC} \gamma$, GSK- $3 \alpha$, and GSK- $3 \beta$ using a specialist service from the MRCProtein Phosphorylation \& Ubiquitylation Unit at the University of Dundee (http://www.kinase-screen.mrc.ac.uk/).

4.2.3. Ex Vivo Tau Hyperphosphorylation Assays. The okadaic acid-induced tau hyperphosphorylation cell model was run in the human neuroblastoma cell line SH-SY5Y. Cells were grown in DMEM supplemented with $10 \% \mathrm{FBS}$ and $1 \%$ penicillin/streptomycin at $37{ }^{\circ} \mathrm{C}$ and $5 \% \mathrm{CO}_{2}$ in an incubator. SH-SY5Y cells were seeded onto a 96-well plate at 60.000 cells per well. After $48 \mathrm{~h}$, cells were preincubated with the compounds at the desired concentration for 1 $\mathrm{h}$, and after that time, okadaic acid (OA) (Sigma Aldrich, catalogue no: 09381$)$ was added at a concentration of $30 \mathrm{nM}$ and incubated for another $24 \mathrm{~h}$. Afterward, cells were incubated with $0.5 \mathrm{mg} / \mathrm{mL}$ MTT solution for at least $4 \mathrm{~h}$ at $37{ }^{\circ} \mathrm{C}$ and $5 \% \mathrm{CO}_{2}$. Then, the culture medium was removed and the formazan crystals attached to the bottom of the plate were dissolved with $200 \mathrm{~mL}$ of DMSO. Finally, UV absorbance was measured at $595 \mathrm{nM}$ in a microplate reader (Varioskan Flash Microplate reader, Thermo Scientific).

\section{ASSOCIATED CONTENT}

\section{Supporting Information}

The Supporting Information is available free of charge at https://pubs.acs.org/doi/10.1021/acs.jmedchem.0c01568.

Predicted potency rankings of Phase I and II compounds from the virtual screening; supplementary figures from calculations; copies of ${ }^{1} \mathrm{H}$ NMR and MS spectra as well as HPLC chromatograms; ${ }^{1} \mathrm{H}$ NMR and ${ }^{13} \mathrm{C}$ NMR characterization data for the nanomolar inhibitors (22-25 and 35) (PDF)

Molecular string formula (SMILES) and \% purities of tested compounds (CSV)

$\mathrm{MD}$ simulation movie of GSK-3 $\beta-23$ protein-ligand complex (MP4)

\section{AUTHOR INFORMATION}

\section{Corresponding Authors}

Ana Martinez - Centro de Investigaciones Biologicas, CSIC, 28040 Madrid, Spain; Centro de Investigación Biomédica en Red de Enfermedades Neurodegenerativas (CIBERNED), Instituto Carlos III, 28031 Madrid, Spain; (Corcid.org/ 0000-0002-2707-8110; Email: ana.martinez@csic.es

Joseph M. Hayes - School of Pharmacy \& Biomedical Sciences, University of Central Lancashire, Preston PR1 2HE, United Kingdom; (1) orcid.org/0000-0002-77459616; Email: jhayes@uclan.ac.uk

\section{Authors}

Matthew P. Davies - School of Pharmacy \& Biomedical Sciences, University of Central Lancashire, Preston PR1 $2 \mathrm{HE}$, United Kingdom

Rocio Benitez - Centro de Investigaciones Biologicas, CSIC, 28040 Madrid, Spain

Concepción Perez - Instituto de Quimica Medica, CSIC, 28006 Madrid, Spain

Sven Jakupovic - AnalytiCon Discovery GmbH, 14473 Potsdam, Germany

Philip Welsby - School of Pharmacy \& Biomedical Sciences, University of Central Lancashire, Preston PR1 2HE, United Kingdom

Klaudia Rzepecka - School of Pharmacy \& Biomedical Sciences, University of Central Lancashire, Preston PR1 $2 \mathrm{HE}$, United Kingdom

Jane Alder - School of Pharmacy \& Biomedical Sciences, University of Central Lancashire, Preston PR1 2HE, United Kingdom

Colin Davidson - School of Pharmacy \& Biomedical Sciences, University of Central Lancashire, Preston PR1 $2 \mathrm{HE}$, United Kingdom

Complete contact information is available at: https://pubs.acs.org/10.1021/acs.jmedchem.0c01568

\section{Notes}

The authors declare no competing financial interest. 


\section{ABBREVIATIONS USED}

$\mathrm{AD}$, Alzheimer's disease; ADMET, absorption, distribution, metabolism, excretion, and toxicity; ATP, adenosine 5' triphosphate; $\mathrm{CDK}$, cyclin-dependent kinase; $\mathrm{DAD}$, diodearray detection; DMEM, Dulbecco's modified Eagle's medium; DMSO, dimethyl sulfoxide; DOLPHIN, Deletion Of Loop PHe-gly-IN; EDTA, ethylenediaminetetraacetic acid; EGTA, ethylene glycol-bis(2-aminoethylether)- $N, N, N^{\prime}, N^{\prime}$-tetraacetic acid; ELSD, evaporative light-scattering detector; ERK, extracellular signal-regulated kinase; FBS, fetal bovine serum; GSK, glycogen synthase kinase; HPLC, high-performance liquid chromatography; $\mathrm{IC}_{50}$, half-maximum inhibitory concentration; IFD, induced-fit docking; KNIME, Konstanz information miner; LogP, logarithm of partition coefficient; MD, molecular dynamics; MS, mass spectrometry; MTT, methylthiazolyldiphenyl-tetrazolium bromide; NMR, nuclear magnetic resonance; OA, okadaic acid; $\mathrm{PBC}$, periodic boundary conditions; PDA, photodiode array; $\mathrm{PDB}$, Protein Data Bank; PKA, protein kinase A; $\mathrm{PKB}$, protein kinase $\mathrm{B}$; PKC, protein kinase C; PME, particle mesh Ewald; RESPA, reversible reference system propagator algorithm; RMSD, root-mean-square deviation; SAR, structure-activity relationship; SGB, surface-generalized Born

\section{REFERENCES}

(1) World Health Organisation. www.who.int (accessed Sept 1, 2020).

(2) Hooper, C.; Killick, R.; Lovestone, S. The GSK3 hypothesis of Alzheimer's disease. J. Neurochem. 2008, 104, 1433-1439.

(3) Hernandez, F.; Lucas, J. J.; Avila, J. GSK3 and tau: Two convergence points in Alzheimer's disease. J. Alzheimer's Dis. 2013, 33, S141-S144.

(4) Takahashi, M.; Tomizawa, K.; Kato, R.; Sato, K.; Uchida, T.; Fujita, S. C.; Imahori, K. Localization and developmental-changes of tau-protein kinase I/glycogen synthase kinase-3-beta in rat-brain. $J$. Neurochem. 1994, 63, 245-255.

(5) Martinez, A.; Perez, D. I. GSK-3 inhibitors: A ray of hope for the treatment of Alzheimer's disease? J. Alzheimer's Dis. 2008, 15, $181-191$.

(6) Martinez, A.; Perez, D. I.; Gil, C. Lessons learnt from glycogen synthase kinase 3 inhibitors development for Alzheimer's disease. Curr. Top. Med. Chem. 2013, 13, 1808-1819.

(7) Eldar-Finkelman, H.; Martinez, A. GSK-3 inhibitors: Preclinical and clinical focus on CNS. Front. Mol. Neurosci. 2011, 4, 32.

(8) King, M. K.; Pardo, M.; Cheng, Y. Y.; Downey, K.; Jope, R. S.; Beurel, E. Glycogen synthase kinase-3 inhibitors: Rescuers of cognitive impairments. Pharmacol. Ther. 2014, 141, 1-12.

(9) Cohen, P.; Goedert, M. GSK3 inhibitors: Development and therapeutic potential. Nat. Rev. Drug Discovery 2004, 3, 479-487.

(10) Aourz, N.; Serruys, A. K.; Chabwine, J. N.; Balegamire, P. B.; Afrikanova, T.; Edrada-Ebel, R.; Grey, A. I.; Kamuhabwa, A. R.; Walrave, L.; Esguerra, C. V.; van Leuven, F.; de Witte, P. A. M.; Smolders, I.; Crawford, A. D. Identification of GSK-3 as a potential therapeutic entry point for epilepsy. ACS Chem. Neurosci. 2019, 10, $1992-2003$.

(11) Morales-García, J. A.; Susin, C.; Alonso-Gil, S.; Perez, D. I.; Palomo, V.; Perez, C.; Conde, S.; Santos, A.; Gil, C.; Martinez, A.; Perez-Castillo, A. Glycogen synthase kinase-3 inhibitors as potent therapeutic agents for the treatment of Parkinson disease. ACS Chem. Neurosci. 2013, 4, 350-360.

(12) Zhou, A. D.; Lin, K. Y.; Zhang, S. C.; Chen, Y. H.; Zhang, N.; Xue, J. F.; Wang, Z. Y.; Aldape, K. D.; Xie, K. P.; Woodgett, J. R.; Huang, S. Y. Nuclear GSK3 beta promotes tumorigenesis by phosphorylating KDM1A and inducing its deubiquitylation by USP22. Nat. Cell Biol. 2016, 18, 954-966.
(13) Meyerson, M.; Enders, G. H.; Wu, C. L.; Su, L. K.; Gorka, C.; Nelson, C.; Harlow, E.; Tsai, L. H. A family of human Cdc2-related protein-kinases. EMBO J. 1992, 11, 2909-2917.

(14) Arfeen, M.; Bharatam, P. V. Design of glycogen synthase kinase-3 inhibitors: An overview on recent advancements. Curr. Pharm. Des. 2013, 19, 4755-4775.

(15) Pandey, M. K.; DeGrado, T. R. Glycogen synthase kinase-3 (GSK-3)-targeted therapy and imaging. Theranostics 2016, 6, 571593.

(16) Liu, Y.; Gray, N. S. Rational design of inhibitors that bind to inactive kinase conformations. Nat. Chem. Biol. 2006, 2, 358-364.

(17) Treiber, D. K.; Shah, N. P. Ins and outs of kinase DFG motifs. Chem. Biol. 2013, 20, 745-746.

(18) Vijayan, R. S. K.; He, P.; Modi, V.; Duong-Ly, K. C.; Ma, H. C.; Peterson, J. R.; Dunbrack, R. L.; Levy, R. M. Conformational analysis of the DFG-out kinase motif and biochemical profiling of structurally validated type II inhibitors. J. Med. Chem. 2015, 58, 466479.

(19) Hari, S. B.; Merritt, E. A.; Maly, D. J. Sequence determinants of a specific inactive protein kinase conformation. Chem. Biol. 2013, 20, 806-815.

(20) Perez, D. I.; Conde, S.; Perez, C.; Gil, C.; Simon, D.; Wandosell, F.; Moreno, F. J.; Gelpi, J. L.; Luque, F. J.; Martinez, A. Thienylhalomethylketones: Irreversible glycogen synthase kinase 3 inhibitors as useful pharmacological tools. Bioorg. Med. Chem. 2009, $17,6914-6925$.

(21) Perez, D. I.; Palomo, V.; Perez, C.; Gil, C.; Dans, P. D.; Luque, F. J.; Conde, S.; Martinez, A. Switching reversibility to irreversibility in glycogen synthase kinase 3 inhibitors: Clues for specific design of new compounds. J. Med. Chem. 2011, 54, 4042-4056.

(22) Redenti, S.; Marcovich, I.; De Vita, T.; Perez, C.; De Zorzi, R.; Demitri, N.; Perez, D. I.; Bottegoni, G.; Bisignano, P.; Bissaro, M.; Moro, S.; Martinez, A.; Storici, P.; Spalluto, G.; Cavalli, A.; Federico, S. A triazolotriazine-based dual GSK-3 beta/CK-1 delta ligand as a potential neuroprotective agent presenting two different mechanisms of enzymatic inhibition. ChemMedChem 2019, 14, 310-314.

(23) Grütter, C.; Simard, J. R.; Mayer-Wrangowski, S. C.; Schreier, P. H.; Perez-Martin, J.; Richters, A.; Getlik, M.; Gutbrod, O.; Braun, C. A.; Beck, M. E.; Rauh, D. Targeting GSK3 from Ustilago maydis: Type-II kinase inhibitors as potential antifungals. ACS Chem. Biol. 2012, 7, 1257-1267.

(24) Friesner, R. A.; Banks, J. L.; Murphy, R. B.; Halgren, T. A.; Klicic, J. J.; Mainz, D. T.; Repasky, M. P.; Knoll, E. H.; Shelley, M.; Perry, J. K.; Shaw, D. E.; Francis, P.; Shenkin, P. S. Glide: A new approach for rapid, accurate docking and scoring. 1. Method and assessment of docking accuracy. J. Med. Chem. 2004, 47, 1739-1749.

(25) Kufareva, I.; Abagyan, R. Type-II kinase inhibitor docking, screening, and profiling using modified structures of active kinase states. J. Med. Chem. 2008, 51, 7921-7932.

(26) Ma, D. L.; Chan, D. S. H.; Wei, G.; Zhong, H. J.; Yang, H.; Leung, L. T.; Gullen, E. A.; Chiu, P.; Cheng, Y. C.; Leung, C. H. Virtual screening and optimization of Type II inhibitors of JAK2 from a natural product library. Chem. Commun. 2014, 50, 1388513888 .

(27) Jacobson, M. P.; Pincus, D. L.; Rapp, C. S.; Day, T. J. F.; Honig, B.; Shaw, D. E.; Friesner, R. A. A hierarchical approach to allatom protein loop prediction. Proteins 2004, 55, 351-367.

(28) Schrödinger, L. L. Release, 2016-3. Maestro; Schrödinger LLC: New York, NY, 2016.

(29) Sterling, T.; Irwin, J. J. ZINC 15-ligand discovery for everyone. J. Chem. Inf. Model. 2015, 55, 2324-2337.

(30) Sherman, W.; Day, T.; Jacobson, M. P.; Friesner, R. A.; Farid, R. Novel procedure for modeling ligand/receptor induced fit effects. J. Med. Chem. 2006, 49, 534-553.

(31) Chatzileontiadou, D. S. M.; Tsika, A. C.; Diamantopoulou, Z.; Delbe, J.; Badet, J.; Courty, J.; Skamnaki, V. T.; Parmenopoulou, V.; Komiotis, D.; Hayes, J. M.; Spyroulias, G. A.; Leonidas, D. D. Evidence for novel action at the cell-binding site of human 
angiogenin revealed by heteronuclear NMR spectroscopy, in silico and in vivo studies. ChemMedChem 2018, 13, 259-269.

(32) Wu, G. S.; Vashishtha, S. C.; Erve, J. C. L. Characterization of glutathione conjugates of duloxetine by mass spectrometry and evaluation of in silico approaches to rationalize the site of conjugation for thiophene containing drugs. Chem. Res. Toxicol. 2010, 23, 13931404.

(33) Georgatza, D.; Gorgogietas, V. A.; Kylindri, P.; Charalambous, M. C.; Papadopoulou, K. K.; Hayes, J. M.; Psarra, A. M. G. The triterpene echinocystic acid and its 3-O-glucoside derivative are revealed as potent and selective glucocorticoid receptor agonists. Int. J. Biochem. Cell Biol. 2016, 79, 277-287.

(34) Feher, M. Consensus scoring for protein-ligand interactions. Drug Discovery Today 2006, 11, 421-428.

(35) Baell, J. B.; Holloway, G. A. New substructure filters for removal of pan assay interference compounds (PAINS) from screening libraries and for their exclusion in bioassays. J. Med. Chem. 2010, 53, 2719-2740.

(36) Schrecengost, R. S.; Green, C. L.; Zhuang, Y.; Keller, S. N.; Smith, R. A.; Maines, L. W.; Smith, C. D. In vitro and in vivo antitumor and anti-inflammatory capabilities of the novel GSK3 and CDK9 inhibitor ABC1183. J. Pharmacol. Exp. Ther. 2018, 365, 107116.

(37) Koehler, D.; Shah, Z. A.; Williams, F. E. The GSK3 beta inhibitor, TDZD-8, rescues cognition in a zebrafish model of okadaic acid-induced Alzheimer's disease. Neurochem. Int. 2019, 122, 31-37.

(38) Lovestone, S.; Boada, M.; Dubois, B.; Hull, M.; Rinne, J. O.; Huppertz, H. J.; Calero, M.; Andres, M. V.; Gomez-Carrillo, B.; Leon, T.; del Ser, T. Investigators, A., A Phase II trial of tideglusib in Alzheimer's disease. J. Alzheimers Dis. 2015, 45, 75-88.

(39) Metin-Armağan, D.; Gezen-Ak, D.; Dursun, E.; Atasoy, I. L.; Karabay, A.; Yilmazer, S.; Ozturk, M. Okadaic acid-induced tau hyperphosphorylation and the downregulation of Pin 1 expression in primary cortical neurons. J. Chem. Neuroanat. 2018, 92, 41-47.

(40) Wu, X. L.; Kosaraju, J.; Tam, K. Y. SLM, a novel carbazolebased fluorophore attenuates okadaic acid-induced tau hyperphosphorylation via down-regulating GSK-3 beta activity in SHSY5Y cells. Eur. J. Pharm. Sci. 2017, 110, 101-108.

(41) Rankin, C. A.; Sun, Q.; Gamblin, T. C. Tau phosphorylation by GSK-3beta promotes tangle-like filament morphology. Mol. Neurodegener. 2007, 2, 12.

(42) Song, J. S.; Yang, S. D. Tau protein kinase I/GSK-3 beta/ kinase FA in heparin phosphorylates tau on Ser199, Thr231, Ser235, Ser262, Ser369, and Ser400 sites phosphorylated in Alzheimer disease brain. J. Protein Chem. 1995, 14, 95-105.

(43) Singh, T. J.; Haque, N.; Grundke-Iqbal, I.; Iqbal, K. Rapid Alzheimer-like phosphorylation of tau by the synergistic actions of non-proline-dependent protein kinases and GSK-3. FEBS Lett. 1995, $358,267-72$.

(44) Garrido, J. J.; Simon, D.; Varea, O.; Wandosell, F. GSK3 alpha and GSK3 beta are necessary for axon formation. FEBS Lett. 2007, $581,1579-86$.

(45) Medina, M.; Garrido, J. J.; Wandosell, F. G. Modulation of GSK-3 as a therapeutic strategy on tau pathologies. Front. Mol. Neurosci. 2011, 4, 24.

(46) Norman, R. A.; Toader, D.; Ferguson, A. D. Structural approaches to obtain kinase selectivity. Trends Pharmacol. Sci. 2012, 33, 273-278.

(47) Pargellis, C.; Tong, L.; Churchill, L.; Cirillo, P. F.; Gilmore, T.; Graham, A. G.; Grob, P. M.; Hickey, E. R.; Moss, N.; Pav, S.; Regan, J. Inhibition of p38 MAP kinase by utilizing a novel allosteric binding site. Nat. Struct. Biol. 2002, 9, 268-272.

(48) Veber, D. F.; Johnson, S. R.; Cheng, H. Y.; Smith, B. R.; Ward, K. W.; Kopple, K. D. Molecular properties that influence the oral bioavailability of drug candidates. J. Med. Chem. 2002, 45, 26152623.

(49) Zhang, H. C.; Bonaga, L. V. R.; Ye, H.; Derian, C. K.; Damiano, B. P.; Maryanoff, B. E. Novel bis(indolyl)maleimide pyridinophanes that are potent, selective inhibitors of glycogen synthase kinase-3. Bioorg. Med. Chem. Lett. 2007, 17, 2863-2868.

(50) Fu, G.; Sivaprakasam, P.; Dale, O. R.; Manly, S. P.; Cutler, S. J.; Doerksen, R. J. Pharmacophore modeling, ensemble docking, virtual screening, and biological evaluation on glycogen synthase kinase-3beta. Mol. Inf. 2014, 33, 610-626.

(51) Søndergaard, C. R.; Olsson, M. H. M.; Rostkowski, M.; Jensen, J. H. Improved treatment of ligands and coupling effects in empirical calculation and rationalization of $\mathrm{pK}(\mathrm{a})$ values. J. Chem. Theory Comput. 2011, 7, 2284-2295.

(52) Harder, E.; Damm, W.; Maple, J.; Wu, C. J.; Reboul, M.; Xiang, J. Y.; Wang, L. L.; Lupyan, D.; Dahlgren, M. K.; Knight, J. L.; Kaus, J. W.; Cerutti, D. S.; Krilov, G.; Jorgensen, W. L.; Abel, R.; Friesner, R. A. OPLS3: A force field providing broad coverage of drug-like small molecules and proteins. J. Chem. Theory Comput. 2016, 12, 281-296.

(53) Li, J. N.; Abel, R.; Zhu, K.; Cao, Y. X.; Zhao, S. W.; Friesner, R. A. The VSGB 2.0 model: A next generation energy model for high resolution protein structure modeling. Proteins 2011, 79, 2794-2812.

(54) Essmann, U.; Perera, L.; Berkowitz, M. L.; Darden, T.; Lee, H.; Pedersen, L. G. A smooth particle mesh Ewald method. J. Chem. Phys. 1995, 103, 8577-8593.

(55) Martyna, G. J.; Klein, M. L.; Tuckerman, M. Nose-Hoover chains - the canonical ensemble via continuous dynamics. J. Chem. Phys. 1992, 97, 2635-2643.

(56) Martyna, G. J.; Tobias, D. J.; Klein, M. L. Constant-pressure molecular-dynamics algorithms. J. Chem. Phys. 1994, 101, 41774189.

(57) Hayes, J. M.; Skamnaki, V. T.; Archontis, G.; Lamprakis, C.; Sarrou, J.; Bischler, N.; Skaltsounis, A. L.; Zographos, S. E.; Oikonomakos, N. G. Kinetics, in silico docking, molecular dynamics, and MM-GBSA binding studies on prototype indirubins, KT5720, and staurosporine as phosphorylase kinase ATP-binding site inhibitors: The role of water molecules examined. Proteins 2011, 79, 703-719.

(58) Baki, A.; Bielik, A.; Molnar, L.; Szendrei, G.; Keseru, G. M. A high throughput luminescent assay for glycogen synthase kinase-3 beta inhibitors. Assay Drug Dev. Technol. 2007, 5, 75-83. 